\title{
Article \\ Thermal Management and Modeling of Forced Convection and Entropy Generation in a Vented Cavity by Simultaneous Use of a Curved Porous Layer and Magnetic Field
}

\author{
Fatih Selimefendigil ${ }^{1}$ and Hakan F. Öztop ${ }^{2,3, *}$ \\ 1 Department of Mechanical Engineering, Celal Bayar University, Manisa 45140, Turkey; \\ fatih.selimefendigil@cbu.edu.tr \\ 2 Department of Mechanical Engineering, Technology Faculty, Furat University, Elazı ğ 23119, Turkey \\ 3 Department of Medical Research, China Medical University Hospital, China Medical University, \\ Taichung 40402, Taiwan \\ * Correspondence: hakanfoztop@firat.edu.tr
}

Citation: Selimefendigil, F.; Öztop, H.F. Thermal Management and Modeling of Forced Convection and Entropy Generation in a Vented Cavity by Simultaneous Use of a Curved Porous Layer and Magnetic Field. Entropy 2021, 23, 152. https://doi.org/10.3390/e23020152

Received: 1 January 2021

Accepted: 22 January 2021

Published: 26 January 2021

Publisher's Note: MDPI stays neutral with regard to jurisdictional clai$\mathrm{ms}$ in published maps and institutional affiliations.

Copyright: $\odot 2021$ by the authors. Licensee MDPI, Basel, Switzerland. This article is an open access article distributed under the terms and conditions of the Creative Commons Attribution (CC BY) license (https:// creativecommons.org/licenses/by/ $4.0 /)$.

\begin{abstract}
The effects of using a partly curved porous layer on the thermal management and entropy generation features are studied in a ventilated cavity filled with hybrid nanofluid under the effects of inclined magnetic field by using finite volume method. This study is performed for the range of pertinent parameters of Reynolds number $(100 \leq \mathrm{Re} \leq 1000)$, magnetic field strength $(0 \leq \mathrm{Ha} \leq 80)$, permeability of porous region $\left(10^{-4} \leq \mathrm{Da} \leq 5 \times 10^{-2}\right)$, porous layer height $\left(0.15 H \leq t_{p} \leq 0.45 H\right)$, porous layer position $\left(0.25 H \leq y_{p} \leq 0.45 H\right)$, and curvature size $(0 \leq b \leq 0.3 H)$. The magnetic field reduces the vortex size, while the average Nusselt number of hot walls increases for Ha number above 20 and highest enhancement is $47 \%$ for left vertical wall. The variation in the average Nu with permeability of the layer is about $12.5 \%$ and $21 \%$ for left and right vertical walls, respectively, while these amounts are $12.5 \%$ and $32.5 \%$ when the location of the porous layer changes. The entropy generation increases with Hartmann number above 20, while there is $22 \%$ increase in the entropy generation for the case at the highest magnetic field. The porous layer height reduced the entropy generation for domain above it and it give the highest contribution to the overall entropy generation. When location of the curved porous layer is varied, the highest variation of entropy generation is attained for the domain below it while the lowest value is obtained at $y_{p}=0.3 \mathrm{H}$. When the size of elliptic curvature is varied, the overall entropy generation decreases from $\mathrm{b}=0$ to $b=0.2 \mathrm{H}$ by about $10 \%$ and then increases by $5 \%$ from $b=0.2 H$ to $b=0.3 H$.
\end{abstract}

Keywords: curved porous layer; vented cavity; convection; finite volume method; nanofluid; entropy generation

\section{Introduction}

Convective heat transfer (CHT) in vented cavities is relevant in a variety of different technological applications such as in electronic cooling, textiles, drying, heating-ventilation, air conditioning, and many other systems [1-4]. Layered porous structures are considered in various applications such as as in fuel cell, solidification, and many other numerous systems. In heat transfer applications, porous inserts may be used for CHT control in channel flow or they may be already available within the system. In the study of Chikh et al. [5], thickness of the porous layer was found to be very effective on the CHT coefficient for the partly porous channels. In the study of Siavashi et al. [6], gradient and layered porous foams were utilized for the performance improvement of CHT in a channel, while best condition of multi-layered foams was obtained by using an optimization routine. In the study of Guerroudj and Kahalerras [7], shape effects of porous blocks were analyzed for mixed CHT and profound impacts of the shape on the heat transfer were reported. Free $\mathrm{CHT}$ in a layered domain of nanofluid and porous media was explored in the work of 
Miroshnichenko et al. [8]. It was noted that the porous media thickness and location were effective on the CHT features. Astanina et al. [9] explored the the effects of porous layer on the CHT a lid-driven cavity. They noted that the average Nu reduced for higher thickness of porous layer.

Magnetic field (MF) effects are explored for the CHT in the vented cavity. The MF effects are relevant in diverse technological applications such as in nuclear reactor coolers, geothermal energy, micro-pumps [10], blood flow through arteries [11], and many other numerous applications in convective heat transfer. In many CHT applications, MF effects were reported to reduce the CHT rate, while in configurations where flow separation exist, MF effects may be opposite due to the suppression of the flow recirculations. Binary particles of nanosized $\mathrm{Ag} / \mathrm{MgO}$ are suspended in water which is considered as the heat transfer fluid (HTF). Nanofluid technology is successfully implemented in many heat transfer system including many renewable energy stems and CHT $[12,13]$. Over the years, many different simulation methods have been developed to correctly describe the nanofluid behavior along with the new correlations for effective nanofluid property relations. Hybrid nanofluids are considered in many heat transfer applications due to the cost, stability and favorable features of thermophysical properties [14,15].

MF effects can be used effectively by utilizing nanoparticles in the HTF. The thermal conductivity enhances by using nanofluid and on the other hand, the electrical conductivity changes as well which will have impacts when MF effects are present. Many studies are considered which take into account the MF effects with nanofluid for CHT control [16-18].

Second law analysis is also performed for various geometric and operating parameters of the thermo-fluid system. The system performance and optimal working conditions can be assessed by utilization of the second law. Minimization of the entropy generation concept has been developed in thermal processes and many factors that were found to be effective in the entropy generation have been explored [19]. In many studies of CHT, entropy generation and exergy loss analysis have been performed by many authors for the case of MF and nanofluid effects [20-22].

In the present study, forced CHT and entropy generation in a VC are numerically explored by using a partly curved porous layer under the impacts of inclined MF by using hybrid nanofluid. The nanofluid thermophysical properties are available from the experimental study. To the best of the authors' knowledge, simultaneous use of a curved porous layer with MF effects has never been considered in VC for thermal management in the cavity. Owing to diverse use of $\mathrm{CHT}$ in vented cavities in various technological applications, the results of this novel thermo-fluid configuration will be used to develop new designs and for further optimization studies.

\section{Mathematical Modeling}

\subsection{Physical Problem}

A ventilated cavity (VC) with one input and one output port is considered as shown in Figure 1. The size of the ports is $w_{i}=w_{o}=0.25 \mathrm{H}$ with $\mathrm{H}$ being the cavity height. In the $\mathrm{VC}$, a curved porous layer is introduced below the inlet port with thickness of $t_{p}$, while $y_{p}$ is the vertical distance between the left bottom corner of VC. An elliptic-shaped curved interface between the porous and fluid layers at center location $\left(x_{c}, y_{c}\right)$ with radii of $a$ and $b$ is included. Fluid with velocity of $\mathrm{u}_{0}$ and $\mathrm{T}_{c}$ cold temperature enter the inlet, and the walls of the $\mathrm{VC}$ are at $\mathrm{T}_{h}$ hot temperature. Hybrid nanofluid with $\mathrm{Ag}$ and $\mathrm{MgO}$ particles is used. A uniform magnetic field (MF) is imposed in nanofluid and porous regions and inclination angle of MF is considered as $\gamma=45^{\circ}$. Natural convection effects with viscous dissipation and radiation and are not considered while the induced MF effects and joule heating are ignored. The flow is 2D, steady, and in the laminar regime while fluid is Newtonian. 


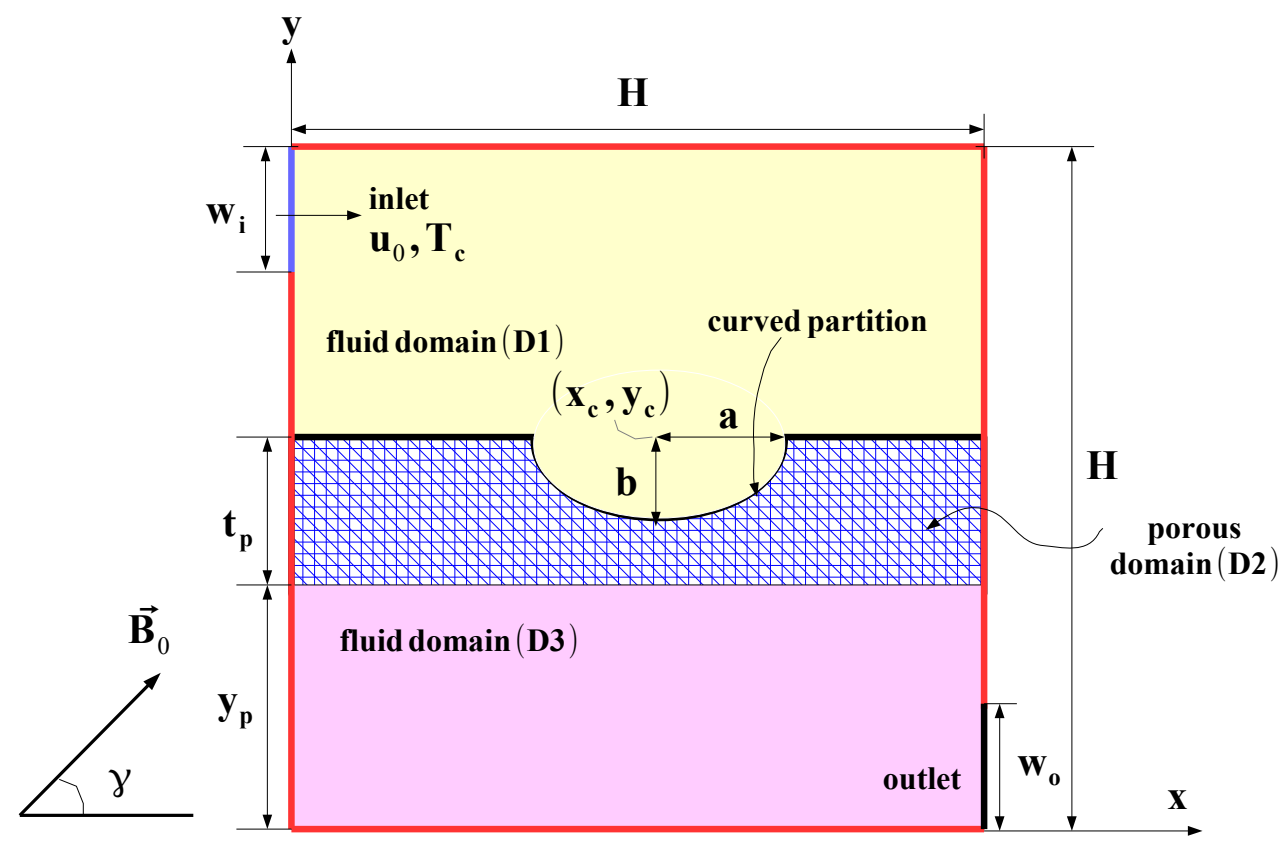

Figure 1. Schematic view of the considered transfer fluid (TF) configuration with curved porous layer.

In the nanofluid regions (D1 and D3), conservation equations (CEs) are stated as [22,23]

$$
\begin{gathered}
\frac{\partial u}{\partial x}+\frac{\partial v}{\partial y}=0 \\
\left(u \frac{\partial u}{\partial x}+v \frac{\partial u}{\partial y}\right)=-\frac{1}{\rho_{n f}} \frac{\partial p}{\partial x}+v_{n f}\left(\nabla^{2} u\right) \\
+\frac{\sigma_{n f} B_{0}^{2}}{\rho_{n f}}\left(v \sin (\gamma) \cos (\gamma)-u \sin ^{2} \gamma\right) \\
\left(u \frac{\partial v}{\partial x}+v \frac{\partial v}{\partial y}\right)=-\frac{1}{\rho_{n f}} \frac{\partial p}{\partial y}+v_{n f}\left(\nabla^{2} v\right) \\
+\frac{\sigma_{n f} B_{0}^{2}}{\rho_{n f}}\left(u \sin (\gamma) \cos (\gamma)-v \cos ^{2} \gamma\right) \\
u \frac{\partial T}{\partial x}+v \frac{\partial T}{\partial y}=\alpha_{n f} \nabla^{2} T .
\end{gathered}
$$

In the porous region (domain D2), the generalized Darcy-Brinkmann Forchheimer model was considered with the CEs [23]:

$$
\begin{gathered}
\frac{\partial u}{\partial x}+\frac{\partial v}{\partial y}=0 \\
\frac{1}{\varepsilon^{2}}\left(u \frac{\partial u}{\partial x}+v \frac{\partial u}{\partial y}\right)=-\frac{1}{\rho_{n f}} \frac{\partial p}{\partial x}+\frac{v_{n f}}{\varepsilon}\left(\nabla^{2} u\right) \\
-v_{n f} \frac{u}{K}-\frac{F_{c}}{\sqrt{K}} u \sqrt{u^{2}+v^{2}}+\frac{\sigma_{n f} B_{0}^{2}}{\rho_{n f}}\left(v \sin (\gamma) \cos (\gamma)-u \sin ^{2} \gamma\right) \\
\frac{1}{\varepsilon^{2}}\left(u \frac{\partial v}{\partial x}+v \frac{\partial v}{\partial y}\right)=-\frac{1}{\rho_{n f}} \frac{\partial p}{\partial y}+\frac{v_{n f}}{\varepsilon}\left(\nabla^{2} v\right) \\
-v_{n f} \frac{v}{K}-\frac{F_{c}}{\sqrt{K}} u \sqrt{u^{2}+v^{2}}+\frac{\sigma_{n f} B_{0}^{2}}{\rho_{n f}}\left(u \sin (\gamma) \cos (\gamma)-v \cos ^{2} \gamma\right)
\end{gathered}
$$




$$
u \frac{\partial T}{\partial x}+v \frac{\partial T}{\partial y}=\alpha_{n f} \nabla^{2} T .
$$

Non-dimensional parameters are written as:

$$
\begin{aligned}
& X=\frac{x}{H}, Y=\frac{y}{H}, U=\frac{u}{v_{0}}, V=\frac{v}{v_{0}}, P=\frac{p}{\rho_{n f} v_{0}^{2}} \theta=\frac{T-T_{c}}{T_{h}-T_{c}} \\
& \mathrm{~F}_{c}=\frac{1.75}{\sqrt{150 \varepsilon^{2}}}, \operatorname{Pr}=\frac{v_{f}}{\alpha_{f}}, \operatorname{Re}=\frac{v_{0} H}{n f}, \mathrm{Ha}=B_{0} H \sqrt{\frac{\sigma_{n f}}{\rho_{n f f}}}, \mathrm{Da}=\frac{K^{2}}{H}
\end{aligned}
$$

Non-dimensional CEs are stated as [22,23]

$$
\begin{gathered}
\frac{\partial U}{\partial X}+\frac{\partial V}{\partial Y}=0 \\
\frac{1}{\left(\delta_{1} \varepsilon\right)^{2}}\left(U \frac{\partial U}{\partial X}+V \frac{\partial U}{\partial Y}\right)=-\frac{\partial P}{\partial X}+d_{1} \frac{1}{\left(\delta_{1} \varepsilon\right) \operatorname{Re}}\left(\nabla^{2} U\right)-d_{1} \frac{U}{\mathrm{DaRe}} \delta_{2} \\
-\frac{F_{c}}{\sqrt{\mathrm{Da}}} U \sqrt{U^{2}+V^{2}} \delta_{2}+d_{2} \frac{\mathrm{Ha}^{2}}{\operatorname{Re}}\left(V \sin (\gamma) \cos (\gamma)-U \sin ^{2} \gamma\right) \\
\frac{1}{\left(\delta_{1} \varepsilon\right)^{2}}\left(U \frac{\partial V}{\partial X}+V \frac{\partial V}{\partial Y}\right)=-\frac{\partial P}{\partial Y}+d_{1} \frac{1}{\left(\delta_{1} \varepsilon\right) \operatorname{Re}}\left(\nabla^{2} V\right)-d_{1} \frac{V}{\mathrm{DaRe}} \delta_{2} \\
-\frac{F_{c}}{\sqrt{\mathrm{Da}}} V \sqrt{U^{2}+V^{2}} \delta_{2}+d_{2} \frac{\mathrm{Ha}^{2}}{\operatorname{Re}}\left(U \sin (\gamma) \cos (\gamma)-V \cos ^{2} \gamma\right) \\
U \frac{\partial \theta}{\partial X}+V \frac{\partial \theta}{\partial Y}=d_{3} \frac{1}{\operatorname{RePr}} \nabla^{2} \theta .
\end{gathered}
$$

with $d_{1}=\frac{v_{n f}}{v_{f}}, d_{2}=\frac{\rho_{f}}{\rho_{n f}} \frac{\sigma_{n f}}{\sigma_{f}}$, and $d_{3}=\frac{\alpha_{n f}}{\alpha_{f}}$. Here, $\delta_{1}$ and $\delta_{2}$ take the value of 1 for domain D2, while $\delta_{1}=\frac{1}{\varepsilon}$ and $\delta_{2}=0$ for the domains D1 and D3.

Boundary conditions are stated as

- VC inlet: $\mathrm{u}=\mathrm{u}_{0}, \mathrm{v}=0, \mathrm{~T}=\mathrm{T}_{c}$

- VC exit: $\frac{\partial u}{\partial x}=\frac{\partial T}{\partial x}=0, v=0$

- Interface between the layers: $u_{f}=u_{p}, v_{f}=v_{p}, k_{f}\left(\frac{\partial T}{x}\right)_{f}=k_{p}\left(\frac{\partial T}{x}\right)_{p}$

- $\quad$ VC walls: $\mathrm{T}=\mathrm{T}_{\mathcal{C}}$

Entropy generation includes the terms due to heat transfer, viscous dissipation, and magnetic field, and it can be written as [22]

$$
\begin{aligned}
& S_{g}=\frac{k_{f}}{T_{0}^{2}}\left[\left(\frac{\partial T}{\partial x}\right)^{2}+\left(\frac{\partial T}{\partial y}\right)^{2}\right]+\frac{\mu}{T_{0}}\left[2\left(\left(\frac{\partial u}{\partial x}\right)^{2}+\left(\frac{\partial v}{\partial y}\right)^{2}\right)+\left(\frac{\partial u}{\partial x}+\frac{\partial v}{\partial y}\right)^{2}\right] \\
& +\frac{\sigma B_{0}^{2}}{T_{0}}(u \sin \gamma-v \cos \gamma)^{2},
\end{aligned}
$$

with $T_{0}=\frac{T_{c}+T_{h}}{2}$.

Nusselt numbers (local and average) are defined as

$$
\mathrm{Nu}_{l}=-\frac{k_{n f}}{k_{f}}\left(\frac{\partial \theta}{\partial n}\right), \mathrm{Nu}_{m}=\frac{1}{L} \int_{0}^{L} \mathrm{Nu}_{l} d l .
$$

where $L$ is the total length for each of the individual hot walls of the VC.

As in the HTF, water with Ag-MgO binary nanoparticles is considered and Table 1 shows the various thermophysical properties [24]. 
The nanofluid density and specific heat are given as [24]

$$
\begin{gathered}
\rho_{n f}=\left[\left(1-\phi_{2}\right)\left(\left(1-\phi_{1}\right) \rho_{f}+\phi_{1} \rho_{s 1}\right)\right]+\phi_{2} \rho_{s 2} \\
\left(\rho c_{p}\right)_{n f}=\left[\left(1-\phi_{2}\right)\left(\left(1-\phi_{1}\right)\left(\rho c_{p}\right)_{f}+\phi_{1}\left(\rho c_{p}\right)_{s 1}\right)\right]+\phi_{2}\left(\rho c_{p}\right)_{s 2}
\end{gathered}
$$

Table 1. Thermophysical properties [24].

\begin{tabular}{cccc}
\hline Property Name & Water & Ag & MgO \\
\hline $\mathrm{k}(\mathrm{W} / \mathrm{mK})$ & 0.61 & 45 & 0.62 \\
$\mu(\mathrm{kg} / \mathrm{m} \mathrm{s})$ & $8.55 \times 10^{-4}$ & - & - \\
$\mathrm{c}_{p}(\mathrm{~J} / \mathrm{kg} \mathrm{K})$ & 4179 & 235 & 955 \\
$\rho\left(\mathrm{kg} / \mathrm{m}^{3}\right)$ & 997.1 & 10,500 & 3560 \\
\hline
\end{tabular}

Experimental data were used for the description of the thermal conductivity and viscosity of the hybrid nanofluid.

Thermal conductivity is stated as [25]

$$
k_{n f}=\left(\frac{0.1747 \times 10^{5}+\phi}{0.1747 \times 10^{5}-0.1498 \times 10^{6} \phi+0.1117 \times 10^{7} \phi^{2}+0.1997 \times 10^{8} \phi^{3}}\right) k_{f}
$$

where $\phi$ is the total solid volume fraction of two different nanoparticles which is defined as:

$$
\phi=\phi_{1}+\phi_{2}
$$

Viscosity of nanofluid is given as [25]:

$$
\mu_{n f}=\left(1+32.795 \phi-7214 \phi^{2}+714600 \phi^{3}-0.1941 \times 10^{8} \phi^{4}\right) \mu_{f} .
$$

Electrical conductivity of the hybrid nanofluid is defied by using the Maxwell relation as [26]

$$
\sigma_{n f}=\sigma_{f}\left(\frac{1+3\left(\frac{\sigma}{\sigma_{f}}-1\right)\left(\phi_{1}+\phi_{2}\right)}{\left(\frac{\sigma}{\sigma_{f}}+2\right)-\left(\frac{\sigma}{\sigma_{f}}-1\right)\left(\phi_{1}+\phi_{2}\right)}\right)
$$

where $\sigma$ denotes the following:

$$
\sigma=\frac{\sigma_{1} \phi_{1}+\sigma_{2} \phi_{2}}{\phi_{1}+\phi_{2}}
$$

Due to the lack of experimental correlation for the effective electrical conductivity of hybrid nanofluid containing $\mathrm{Ag} / \mathrm{MgO}$ binary particles in water, the above model is preferred which was also used in the study in [27]. However, in the literature, different models that were derived from the experimental data were available for the electrical conductivity of nanofluid with several different nanoparticles. In the study of Selimefendigil and Öztop [28], effects of different electrical conductivity models for water-alumina nanofluids on the mixed convection features were explored. Minea and Luciu [29] performed experimental work for the electrical conductivity of $\mathrm{Al}_{2} \mathrm{O}_{3}$ nanofluids, and they developed a correlation for the effective electrical conductivity of nanofluid which dependent upon the solid volume fraction and temperature. A strong impact of the volume fraction was noted. In the experimental work of Chereches and Minea [30], electrical conductivity of hybrid nanofluids with water as base fluid and $\mathrm{Al}_{2} \mathrm{O}_{2}, \mathrm{TiO}_{2}$ and $\mathrm{SiO}_{2}$ as nanoparticles was examined for the temperature range of $20^{\circ} \mathrm{C}$ and $60{ }^{\circ} \mathrm{C}$. Several relations for the effective electrical conductivity of hybrid nanofluid were developed. 


\subsection{Solution Method and Code Validation}

As the solution of the CEs with boundary conditions, the finite volume method (FVM) is utilized. A commercial computational fluid dynamics code based on FVM, Fluent [31], is used as the solver. After using the appropriate discretization schemes for diffusion and convective terms, the algebraic equations are obtained as [32]

$$
a_{p} \phi_{p}=\sum a_{n} \phi_{n}+s
$$

where $p$ and $n$ are the node point and relevant neighbor node, respectively.

The QUICK (Quadratic Upstream Interpolation for Convective Kinematics) scheme is utilized for convective terms discretization [33] while SIMPLE (Semi-Implicit Method for Pressure Linked Equations) is selected for the velocity-pressure coupling [34]. The solution is made by using the Gauss-Siedel point-by-point iterative method and algebraic multigrid method [31]. The residual which is in normalized form is stated as

$$
R^{\phi}=\frac{\sum_{\text {all cells }}\left|a_{p} \phi_{p}-a_{n} \phi_{n}-s\right|}{\sum_{\text {all cells }}\left|a_{p} \phi_{p}\right|} .
$$

Solution convergence is obtained for residual value less than $10^{-8}$ (for all dependent variables). Under-relaxation parameters are used, and they are taken as 0.6 for velocity and temperature.

Different grid sizes are tested for assurance of mesh independence of the solution. Figure 2a shows the average $\mathrm{Nu}$ considering all hot walls of VC at two different Hartmann numbers for various grids. G4 with 21,320 elements is selected, while the mesh distribution is given in Figure $2 b$. The mesh is refined near the walls and at the interface of domains D1 and D2, and D2 and D3.

Code validation was performed. In the first work, numerical study results of [35] were used where $\mathrm{CHT}$ in a vented cavity was explored. Figure 3 shows the comparison results of average $\mathrm{Nu}$ for different Reynolds numbers while highest deviation below $3.5 \%$ is obtained. In another validation study, CHT in a porous cavity was considered. Table 2 shows the comparison results of average $\mathrm{Nu}$ values with different sources at two values of Rayleigh number while the agreement between the results seems satisfactory. The last validation is performed by using the numerical results in Ref. [36] where CHT in a cavity with magnetic field effects was considered. Table 3 presents the comparison results of average $\mathrm{Nu}$ for two different Rayleigh numbers at Hartmann number of 30. The highest deviation is below $4 \%$.

Table 2. Average Nu comparisons in a differentially heated porous cavity.

\begin{tabular}{ccc}
\hline & Ra $=\mathbf{~ 1 0 0}$ & Ra $=\mathbf{1 0 0 0}$ \\
\hline Ref. in [37] & 3.160 & 14.060 \\
Ref. in [38] & 3.002 & 13.726 \\
Ref. in [39] & 3.115 & 13.667 \\
Present code & 3.112 & 13.711 \\
\hline
\end{tabular}

Table 3. Average Nu comparison for convective heat transfer (CHT) under the effects of magnetic field at $\mathrm{Ha}=30$ with different Rayleigh numbers.

\begin{tabular}{lcc}
\hline & $\mathbf{R a}=\mathbf{1 0}^{\mathbf{3}}$ & $\mathbf{R a}=\mathbf{1 0}^{\mathbf{5}}$ \\
\hline Current study & 1.032 & 3.206 \\
Ref. in [36] & 1.002 & 3.150 \\
\hline
\end{tabular}




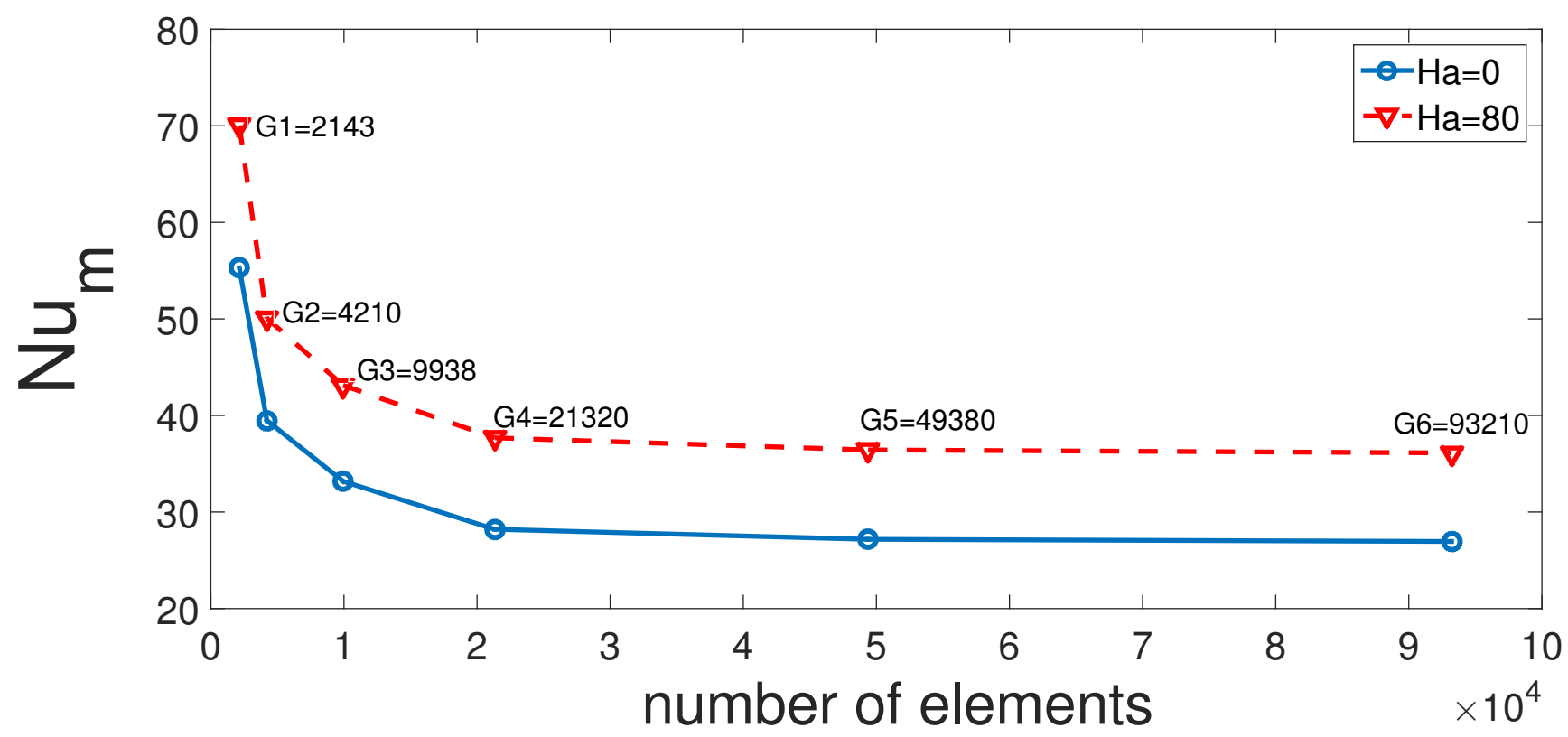

(a)

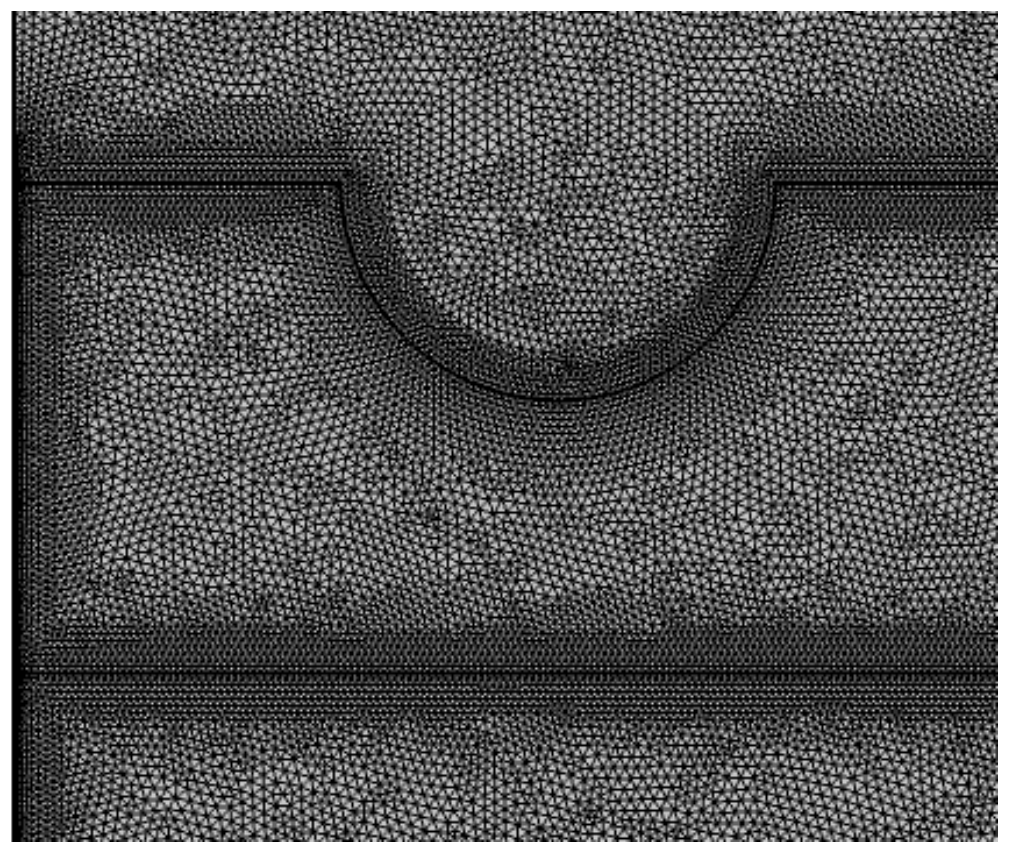

(b)

Figure 2. Grid independence results: The average $\mathrm{Nu}$ comparisons at two MF strength considering different grid sizes (a) and grid distribution (b). 


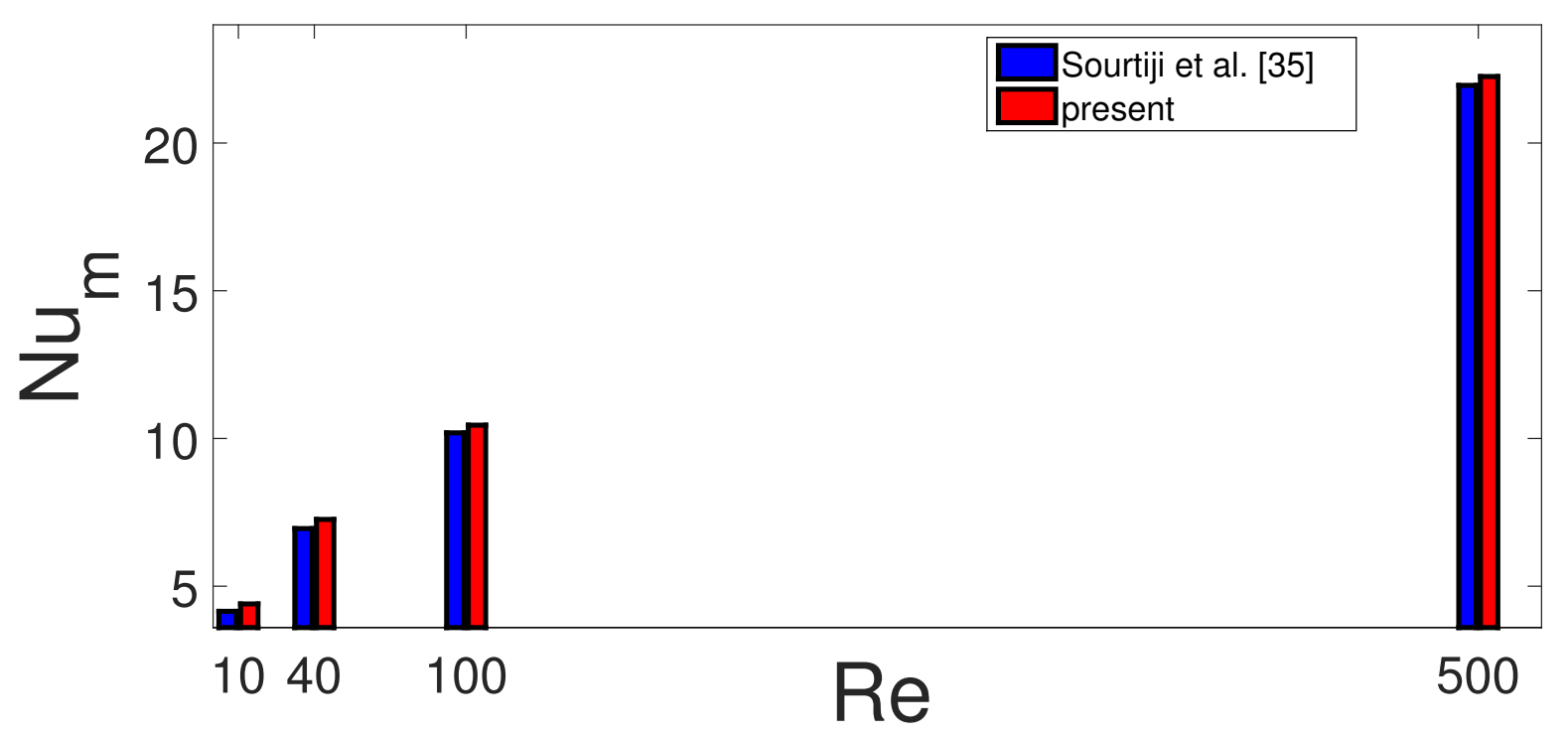

(a)

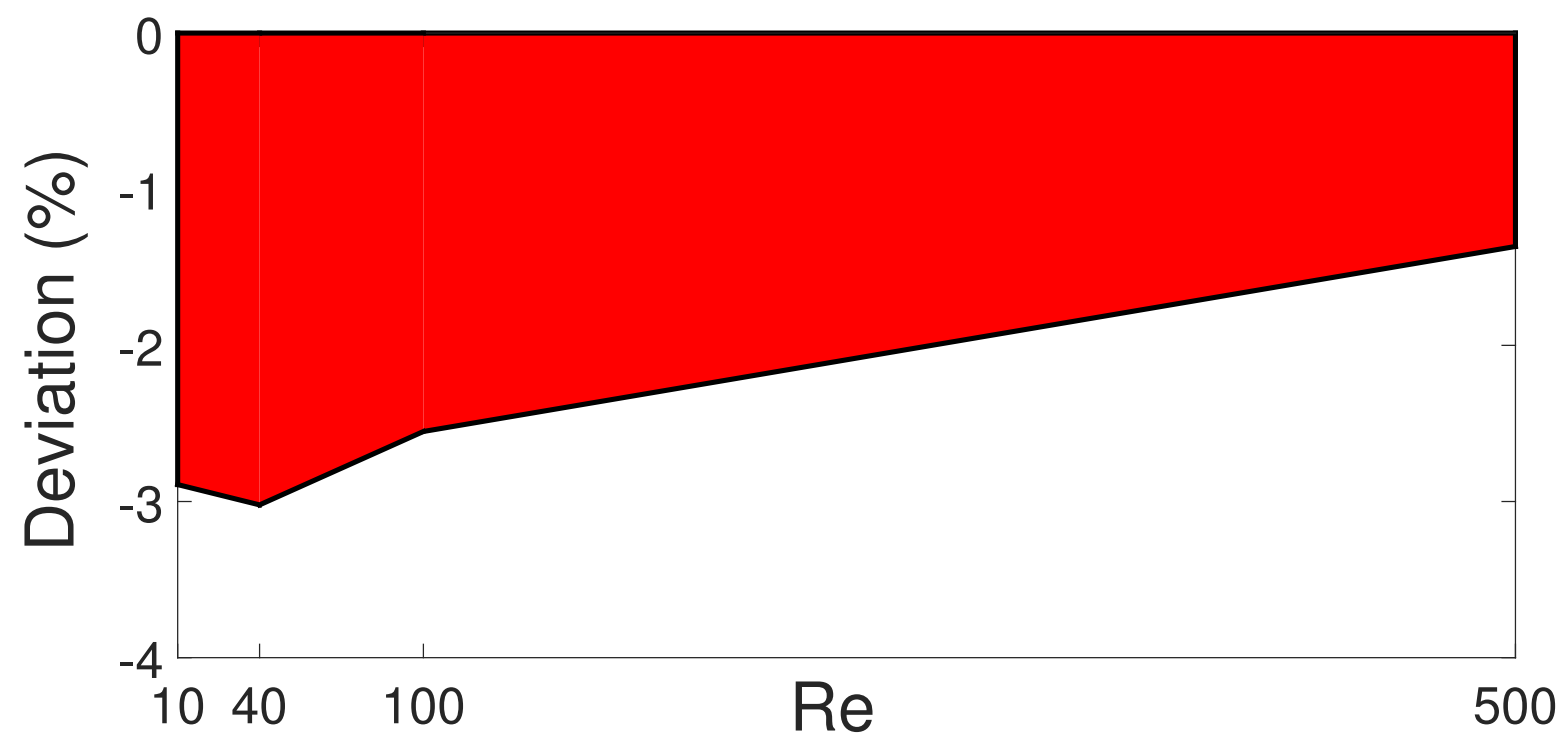

(b)

Figure 3. Comparison of average $\mathrm{Nu}$ for different Reynolds number at $\mathrm{Ri}=10$ (a) and deviation in percentage between the present work and reference study in [35] (b).

\section{Results and Discussion}

Forced convective heat transfer (CHT) in a VC with a partly curved porous layer under uniform MF impacts are studied. Hybrid nanofluid is utilized as the HTF. The study is conducted for the pertinent parameters of Reynolds number $(100 \leq \operatorname{Re} \leq 1000)$, MF strength $(0 \leq \mathrm{Ha} \leq 80)$, permeability of porous region $\left(10^{-4} \leq \mathrm{Da} \leq 5 \times 10^{-2}\right)$, height of porous layer $\left(0.15 \mathrm{H} \leq t_{p} \leq 0.45 \mathrm{H}\right)$, location of porous layer $\left(0.25 \mathrm{H} \leq y_{p} \leq 0.45 \mathrm{H}\right)$, and elliptic curvature radius $(0 \leq b \leq 0.3 H)$. The other radius of the ellipse is taken as $a=0.2 \mathrm{H}$ while the center location is chosen as $\left(x_{c}, y_{c}\right)=\left(0.5 H, y_{p}+t_{p}\right)$. The hybrid particles solid volume fraction is chosen as $\phi=2 \%$ while MF inclination angle is $\gamma=45^{\circ}$.

A uniform inclined MF is imposed in the computational domain of VC. In the absence of MF, recirculation zones are established below and above the main flow stream (Figure 4). The size of the vortex below the inlet is gradually reduced with higher MF strength while 
the vortex near the upper corner disappears with MF. The MF effects resulted in thinner thermal boundaries along the hot walls of the VC. The inclined MF is seen to suppress the recirculation zones within the VC.

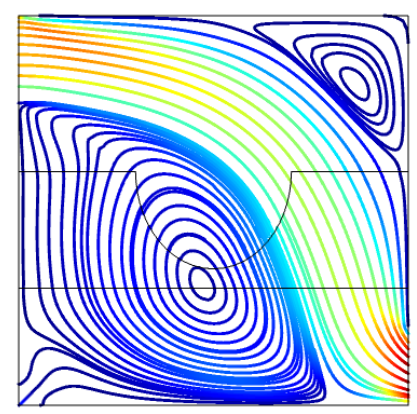

(a)

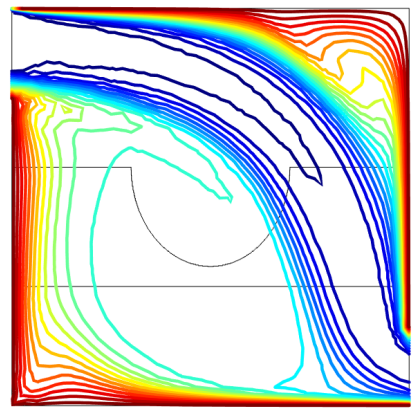

(e)

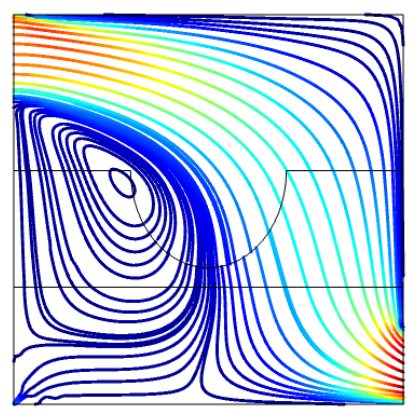

(b)

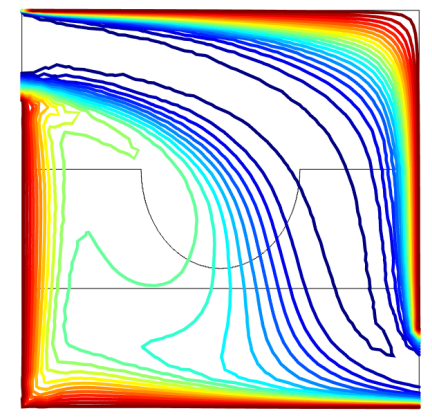

(f)

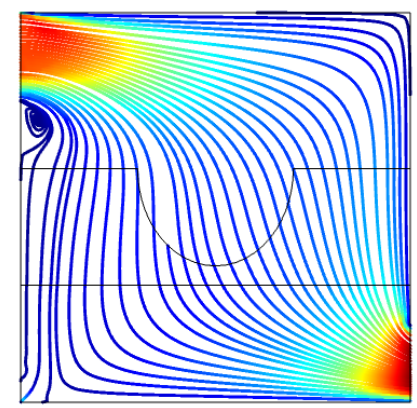

(c)

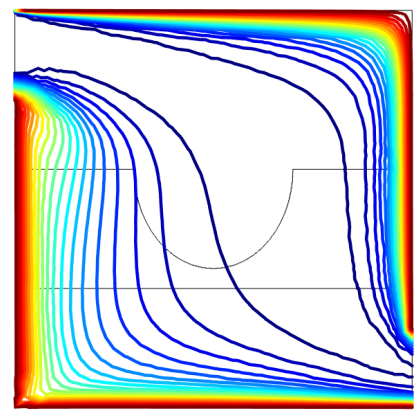

(g)

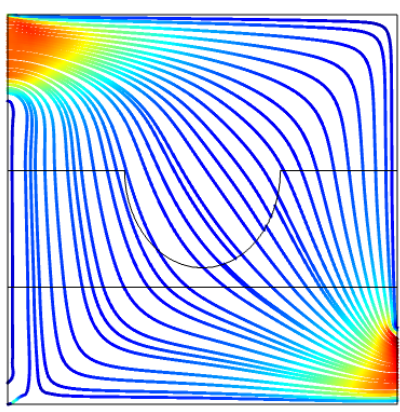

(d)

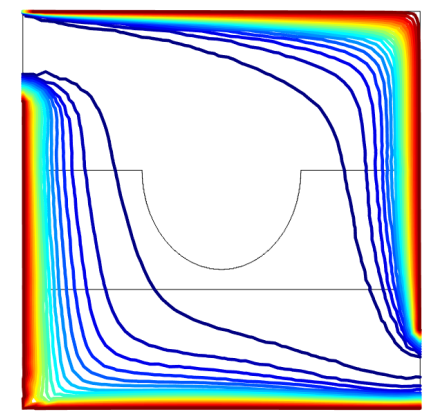

(h)

Figure 4. MF strength impacts on the variation of streamlines and isotherms ( $\operatorname{Re}=500, \gamma=45^{\circ}, \mathrm{Da}=5 \times 10^{-2}, \mathrm{t}_{p}=0.3 \mathrm{H}$, $\mathrm{y} p=0.3 \mathrm{H}, \mathrm{b}=0.25 \mathrm{H}$ ). (a) Ha=0, (b) $\mathrm{Ha}=20$, (c) $\mathrm{Ha}=40$, (d) $\mathrm{Ha}=80,(\mathbf{e}) \mathrm{Ha}=0$, (f) Ha = 20, (g) Ha = 40, (h) Ha = 80.

Figure 5 presents the average $\mathrm{Nu}\left(\mathrm{Nu}_{m}\right)$ variation for each of the hot walls for varying Reynolds number and MF strength considering each of the hot walls of the VC. Here, W1,

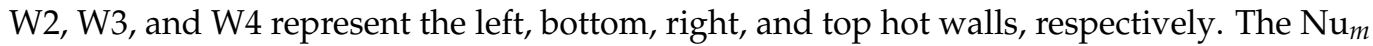
increases with higher Re, while the highest impact is seen for left and right walls of the VC. For the left hot wall, this is attributed to the vortex size reduction below inlet and more cold fluid interacts with the hot wall. As the MF strength is increased to $\mathrm{Ha}=20$, the $\mathrm{Nu}_{m}$ for bottom and left wall reduces and increases thereafter. The MF acts in away to rise the average $\mathrm{Nu}_{m}$ for other walls of the $\mathrm{VC}$. The highest increment in the average $\mathrm{Nu}$ is seen for hot wall W1 (47\%), and it is followed by walls W2 (38\%) and W4 (38\%) as the cases in the absence and presence of MF are compared. This could be attributed to the Lorentz forces of the MF, the vortex which is occurred below inlet port reduces with higher MF strength. However, the average $\mathrm{Nu}$ reduces by about $6.8 \%$ for wall $\mathrm{W} 3$. 


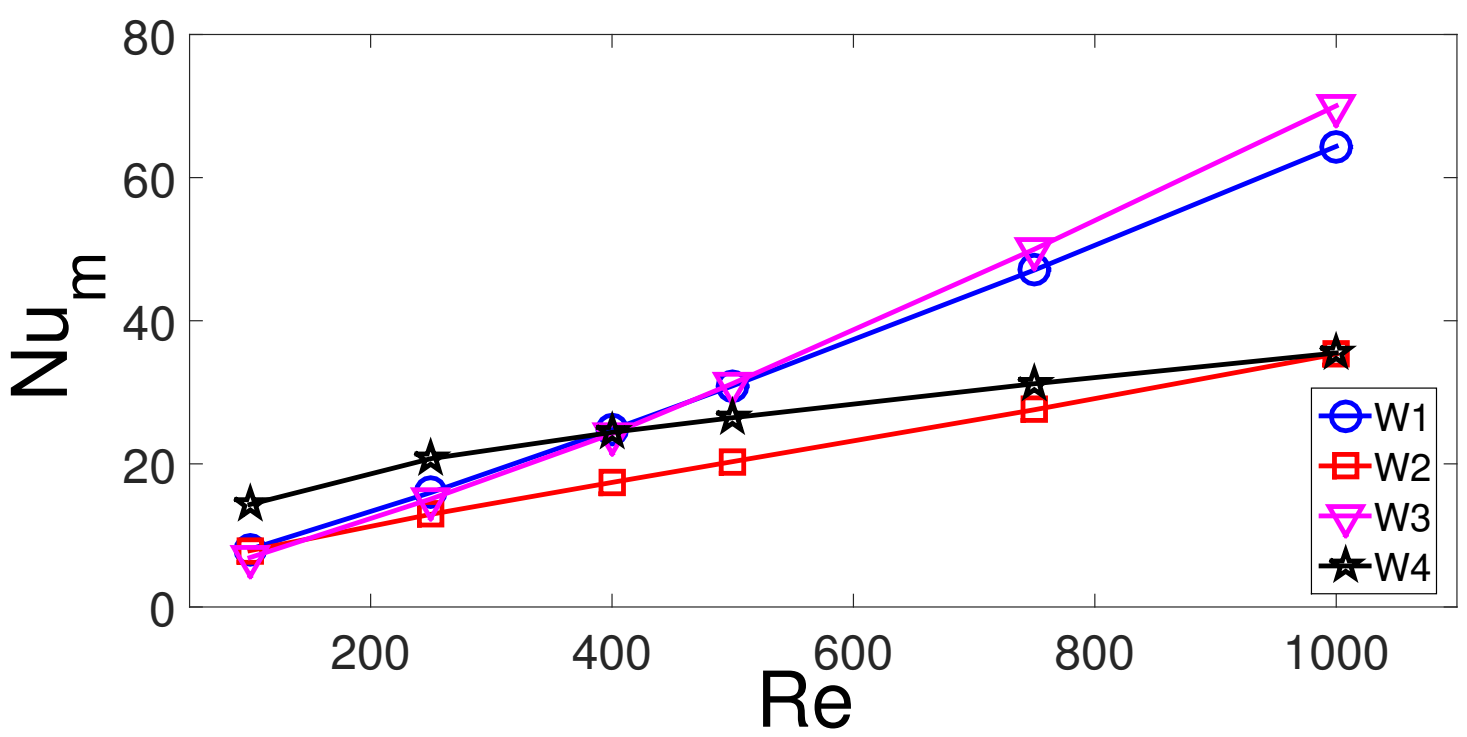

(a)

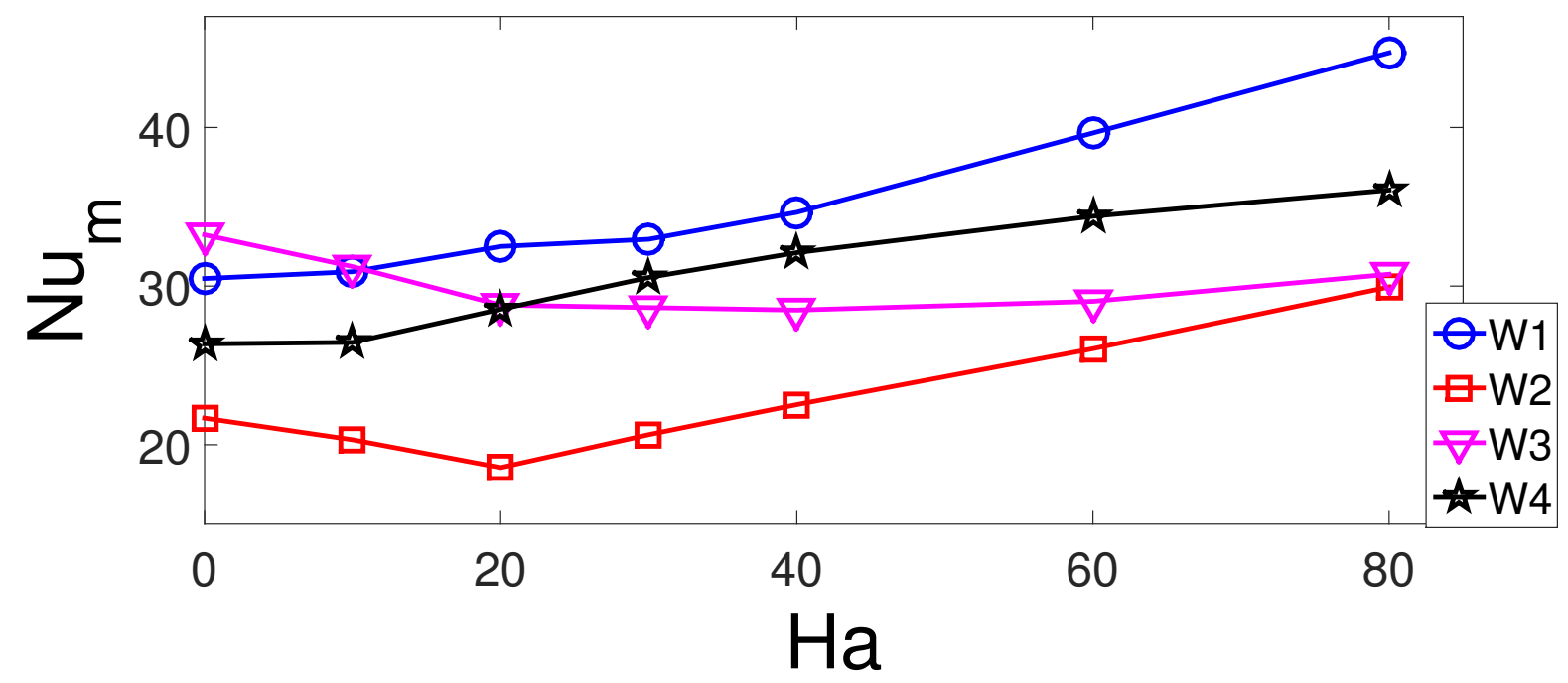

(b)

Figure 5. Effects of Re number and MF strength on the average Nu variation of hot walls $\left(\gamma=45^{\circ}, \mathrm{Da}=5 \times 10^{-2}, \mathrm{t}_{p}=0.3 \mathrm{H}\right.$, $\left.\mathrm{y}_{p}=0.3 \mathrm{H}, \mathrm{b}=0.25 \mathrm{H}\right)$. (a) $\mathrm{Ha}=10$, (b) $\operatorname{Re}=500$.

The effects of permeability of the porous region (D2) on the FP and TP variations are shown in Figure 6. The vortex size below the inlet increases with higher permeability of the curved porous layer while the core size moves toward the bottom wall. There is also some slight variations of the upper corner vortex of the VC with varying Darcy numbers. There are $12.5 \%$ and $6.7 \%$ increases in the average Nu for hot walls W1 and W2, respectively, when highest and lowest permeability cases are compared (Figure 7). For the lowest permeability of the porous layer, it deflects more fluid flow toward the left and bottom walls which reduces the separated flow region below the inlet. However, for right and top hot walls, the average $\mathrm{Nu}$ rises with higher permeability of the porous layer which are $21 \%$ and $12.5 \%$ for hot walls W3 and W4. 


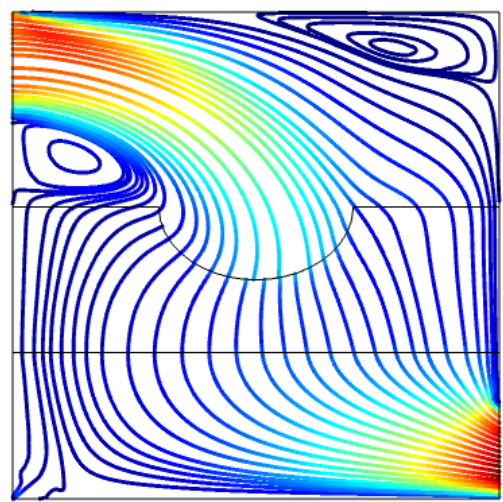

(a)

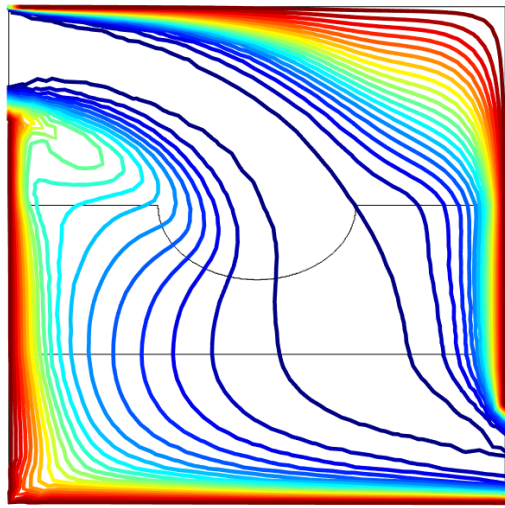

(d)

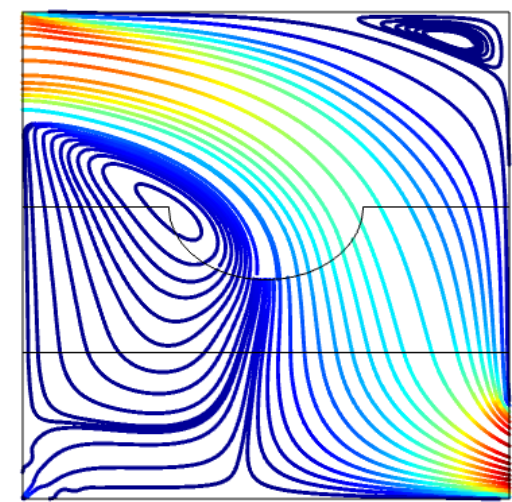

(b)

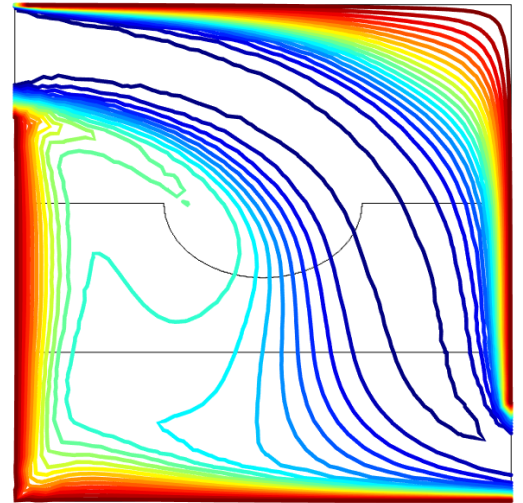

(e)

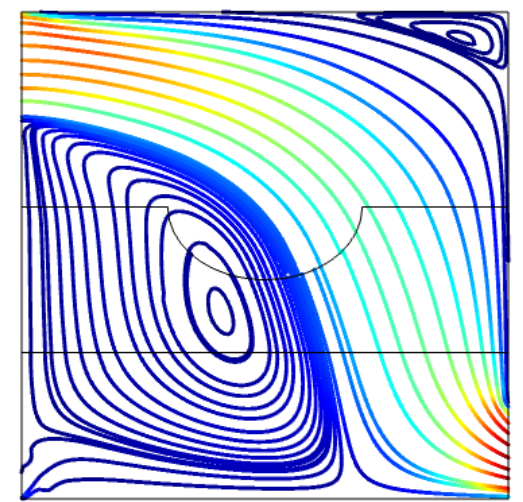

(c)

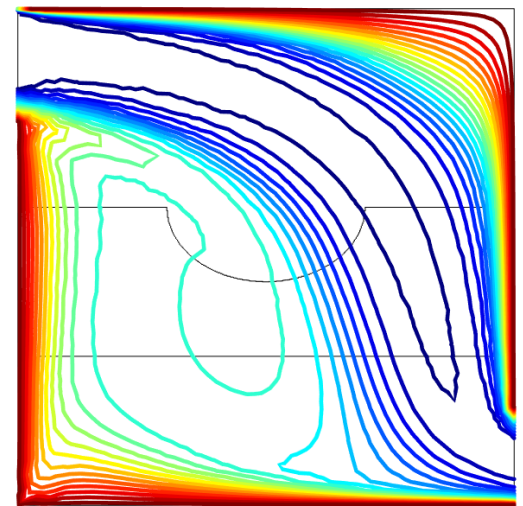

(f)

Figure 6. Impacts of porous layer permeability on the variation of streamlines and isotherms $\left(\operatorname{Re}=500, \mathrm{Ha}=15, \gamma=45^{\circ}\right.$, $\left.\mathrm{t}_{p}=0.3 \mathrm{H}, \mathrm{y}_{p}=0.3 \mathrm{H}, \mathrm{b}=0.25 \mathrm{H}\right)$. (a) $\mathrm{Da}=10^{-4}$, (b) $\mathrm{Da}=10^{-3}$, (c) $\mathrm{Da}=5 \times 10^{-2}$, (d) $\mathrm{Da}=10^{-4},(\mathbf{e}) \mathrm{Da}=10^{-3}$, (f) $\mathrm{Da}=5 \times 10^{-2}$.

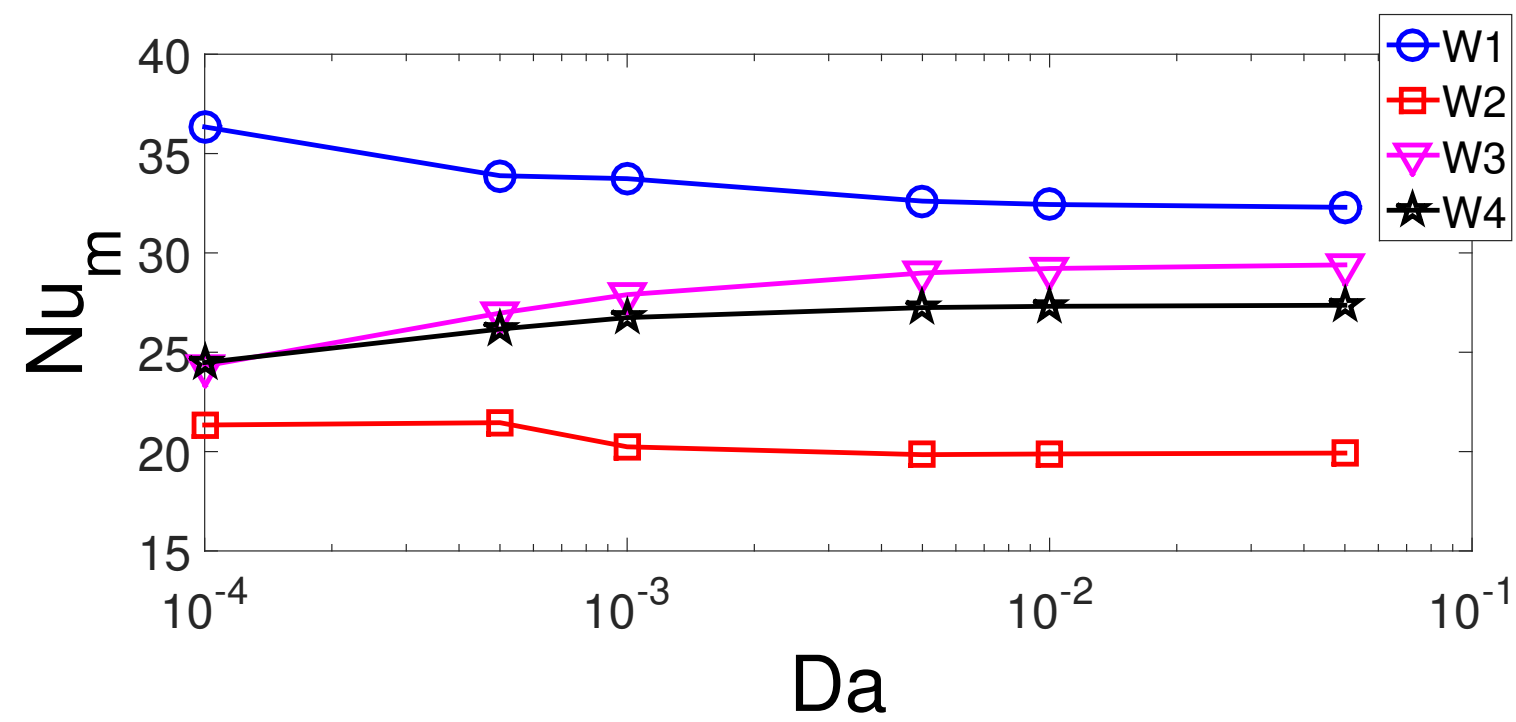

Figure 7. Average $\mathrm{Nu}$ variation of individual hot walls with varying values of porous layer permeability $(\operatorname{Re}=500, \mathrm{Ha}=15$, $\left.\gamma=45^{\circ}, \mathrm{t}_{p}=0.3 \mathrm{H}, \mathrm{y}_{p}=0.3 \mathrm{H}, \mathrm{b}=0.25 \mathrm{H}\right)$. 
Impacts of porous layer geometrical parameters on the variation of FP are shown in Figure 8. As the height of the porous layer is increased, the vortex below the inlet reduces in size, while the core center moves toward the inlet and the porous layer effects become important. The upper corner vortex elongates slightly with higher height of the porous layer. The impacts of porous layer location on FP distribution are slight while effects are more profound for changing the curved size of the layer. Two core centers are seen in the vortex below the inlet for case without curvature of the layer while upper corner vortices are also slightly affected with varying $b$ values. The highest variation in the average $\mathrm{Nu}$ for varying porous layer height is obtained for left hot wall W1 which is attributed to the redistribution of the vortex below inlet port. It increases by about $6 \%$ from $t_{p}=0.15 \mathrm{H}$ to $t_{p}=0.3 \mathrm{H}$ and then is is reduced by about $9 \%$ from $t_{p}=0.3 \mathrm{H}$ to $t_{p}=0.45 \mathrm{H}$. For other walls, the variations of average $\mathrm{Nu}$ are below $4 \%$ (Figure 9). As the location of porous zone changes, the highest impact on average $\mathrm{Nu}$ is seen for hot wall $\mathrm{W} 3$ above the exit port and the variation is about $32.5 \%$ when comparing the values between lowest and highest $y_{p}$. For hot wall W1, the average Nu reduces and the highest variation with $y_{p}$ is $12.5 \%$. As the curvature of the porous layer increases, there is only $4.5 \%$ and $2.5 \%$ variation of the average $\mathrm{Nu}$ for hot walls $\mathrm{W} 1$ and $\mathrm{W} 2$, while the impacts become effective for walls $\mathrm{W} 3$ and $\mathrm{W} 4$. The lowest average $\mathrm{Nu}$ is obtained at $b=0.2 \mathrm{H}$ for hot wall $\mathrm{W} 3$ while for this case, the average $\mathrm{Nu}$ is highest for wall $\mathrm{W} 4$. The amount of variations in the average $\mathrm{Nu}$ is $8 \%$ for wall W3 and $24 \%$ for wall W4.

The entropy generation (EG) studies are performed for the individual domain and whole domain of the computational model. Effects of MF strength on the variation of EG of domains D1, D2, and D3 and whole domain are shown in Figure 10a,b. The EG is highest for domain D1 and the values increase for Ha number higher than 20. This could be attributed to the higher irreversibility in heat transfer with higher MF strength. When normalized EG $\left(S^{*}\right)$ values are compared, there is almost $22 \%$ increase for the cases with and without MF effects. The height of the porous layer resulted in reduction of EG for domain D1 which has the highest contribution to the overall normalized EG. There is a $5 \%$ reduction when cases at $t_{p}=0.15 \mathrm{H}$ and $t_{p}=0.3 \mathrm{H}$ are compared. The location of the curved porous layer has highest impact on the variation of normalized EG of the domain D3 while the lowest EG is attained at $y_{p}=0.3 \mathrm{H}$ when all domains are considered which is again may be attributed to the lower irreversibility of heat transfer at this configuration. The size of the elliptic curvature has the highest impact on the normalized EG for domain D1 while the overall EG reduces until $b=0.2 \mathrm{H}$ by about $10 \%$ and then increases by about $5 \%$ at $b=0.3 H$ (Figure 11). 


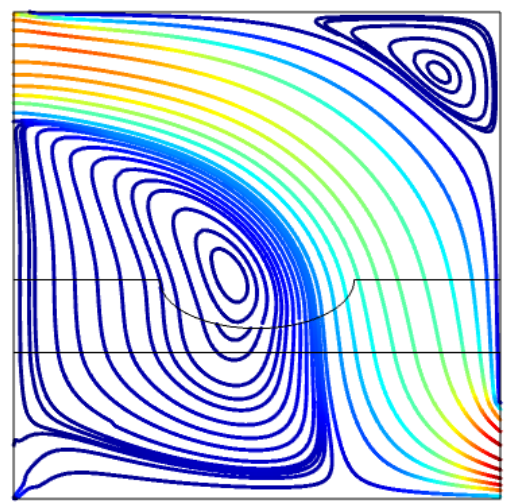

(a)

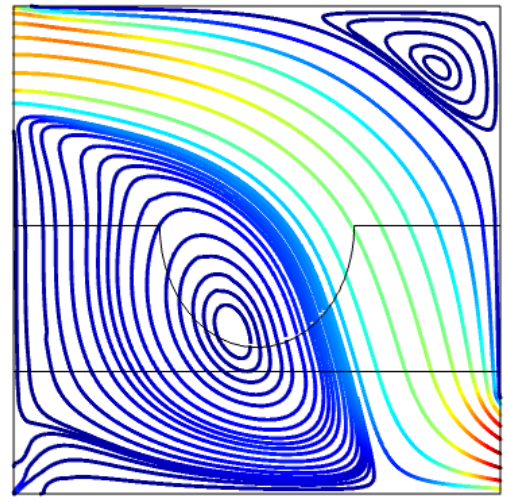

(d)

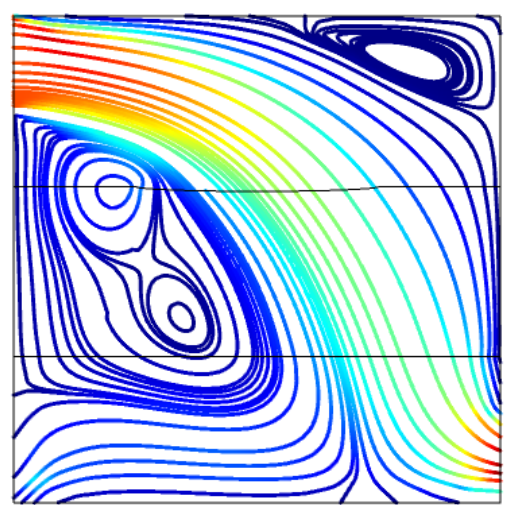

$(\mathrm{g})$

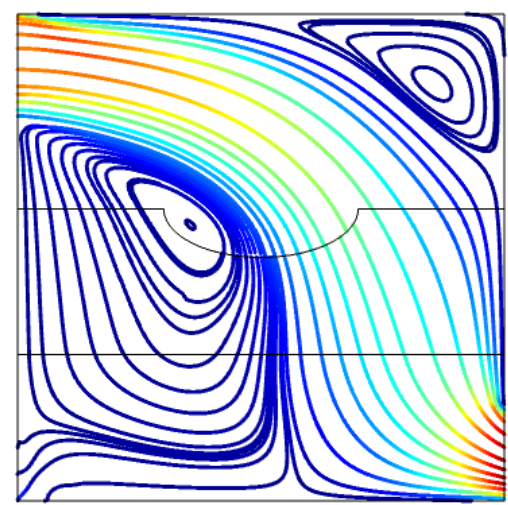

(b)

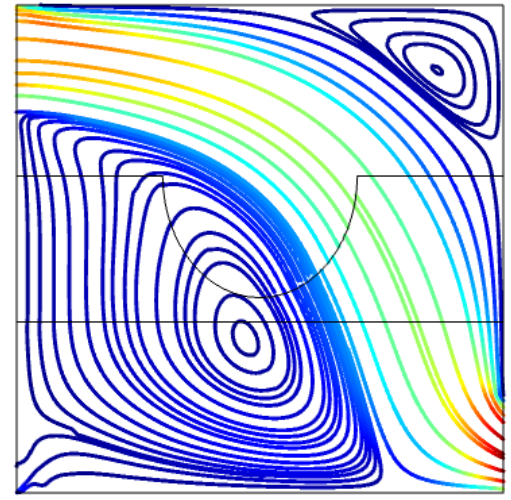

(e)

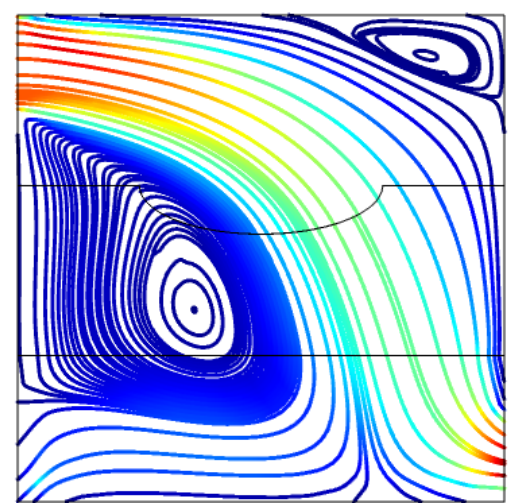

(h)

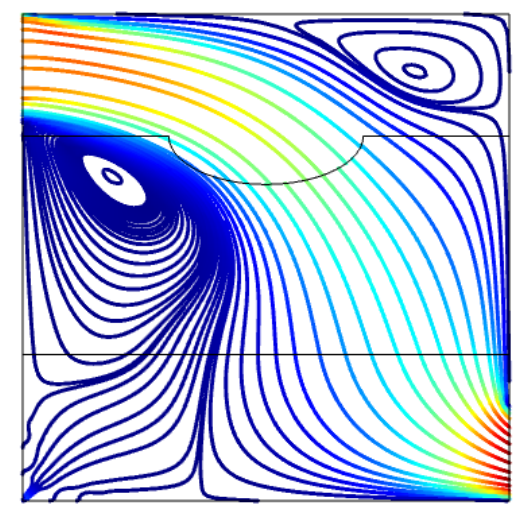

(c)

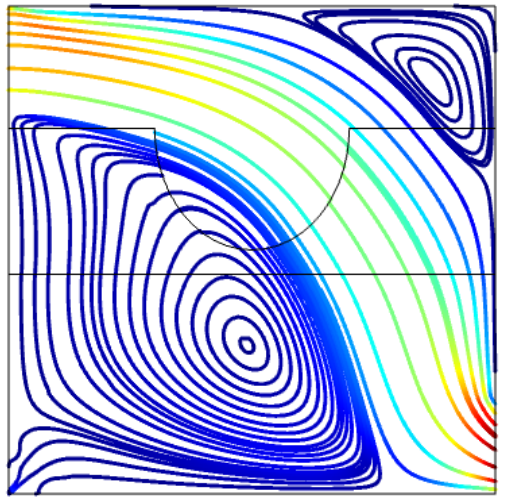

(f)

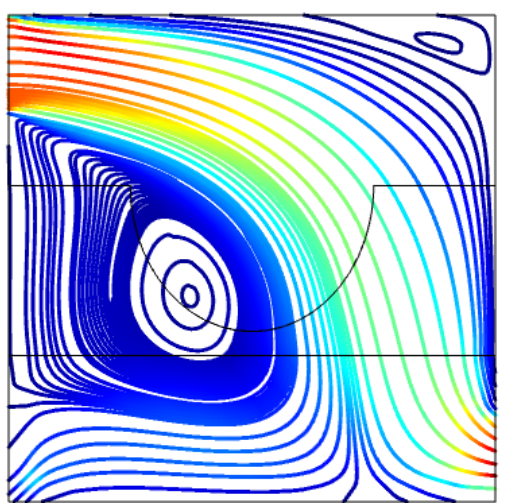

(i)

Figure 8. Impacts of curved porous layer partition geometric parameters on the streamline distributions $(\operatorname{Re}=500, \mathrm{Ha}=15$, $\gamma=45^{\circ}, \mathrm{Da}=5 \times 10^{-2}$ ). (a) $\mathrm{t}_{p}=0.1 H$, (b) $\mathrm{t}_{p}=0.3 H$, (c) $\mathrm{t}_{p}=0.45 H$, (d) $\mathrm{y}_{p}=0.25 H,(\mathbf{e}) \mathrm{y}_{p}=0.3 H,(\mathbf{f}) \mathrm{y}_{p}=0.45 H$, (g) $\mathrm{b}=0$, (h) $\mathrm{b}=0.1 \mathrm{H}$, (i) $\mathrm{b}=0.3 \mathrm{H}$. 


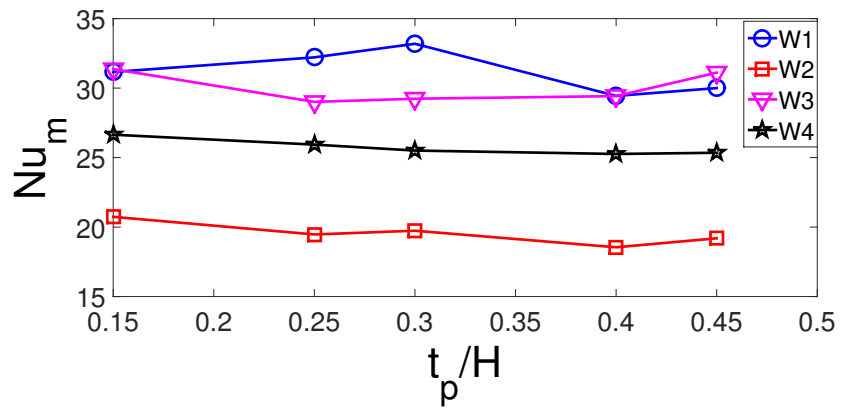

(a)

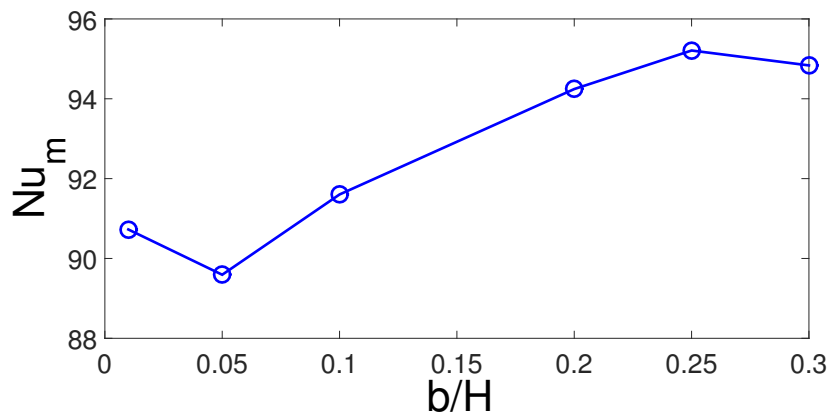

(c)

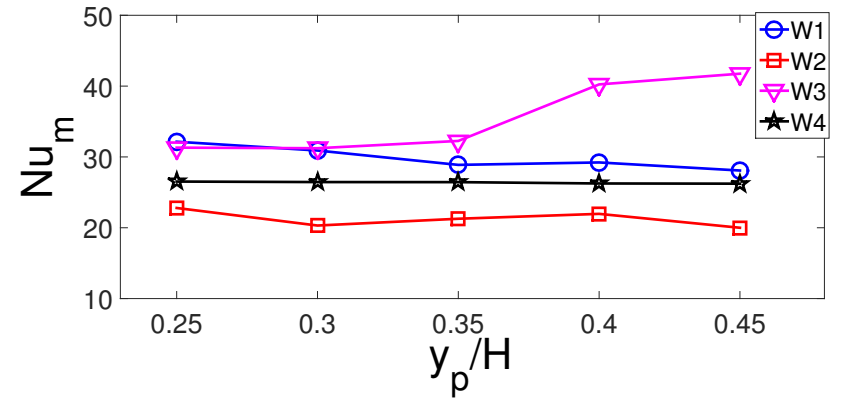

(b)

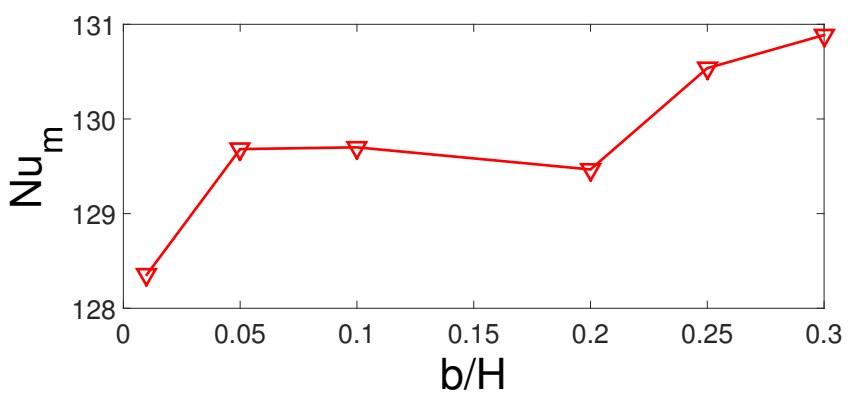

(d)

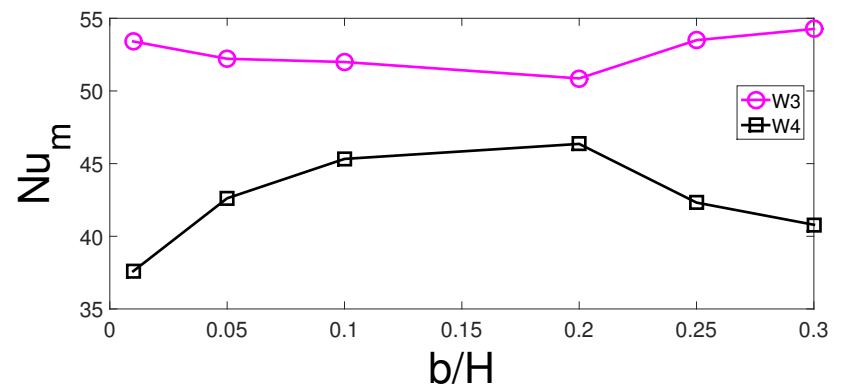

(e)

Figure 9. Average Nu variation of hot walls for varying geometric parameters of the curved porous layer partition $(\operatorname{Re}=500$, $\mathrm{Ha}=15, \gamma=45^{\circ}, \mathrm{Da}=5 \times 10^{-2}$ ). (a) W1, W2, W3 and W4, (b) W1, W2, W3 and W4, (c) W1, (d) W2, and (e) W3 and W4. 


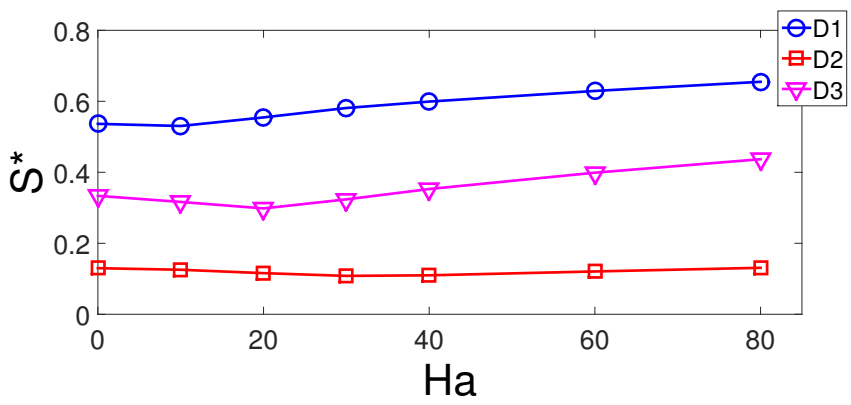

(a)

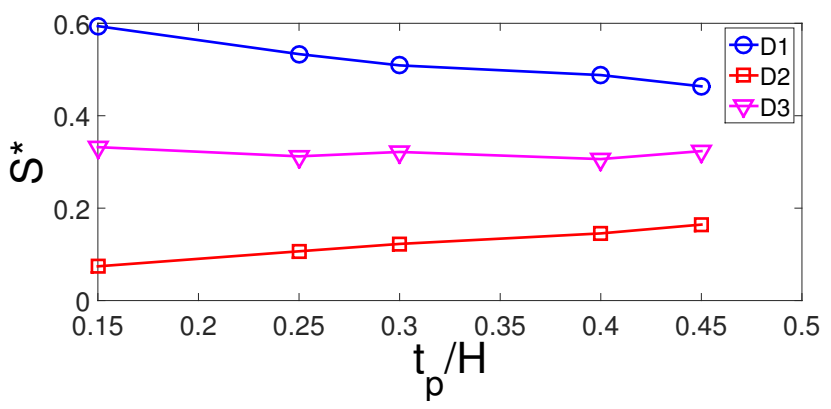

(c)

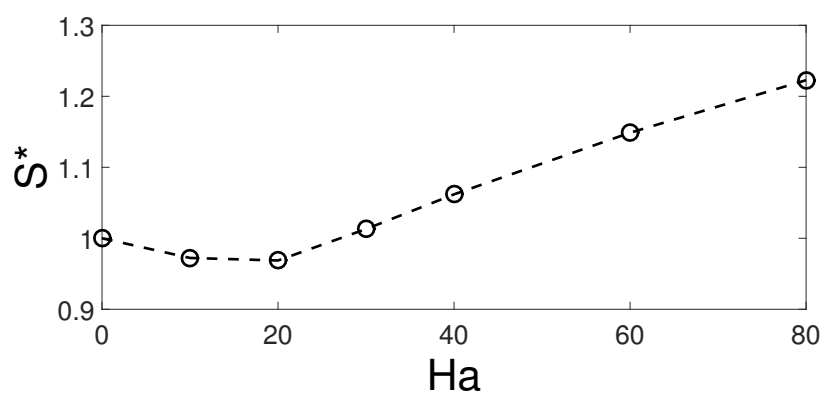

(b)

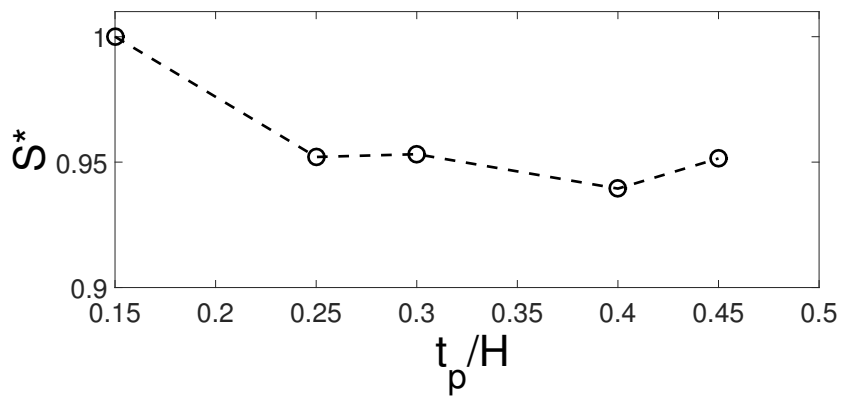

(d)

Figure 10. Normalized entropy generation $\left(S^{*}\right)$ variation of individual domains and all domains with respect to changes in MF strength $(\mathbf{a}, \mathbf{b})$ and porous layer thickness $(\mathbf{c}, \mathbf{d})\left(\operatorname{Re}=500, \gamma=45^{\circ}, \mathrm{Da}=5 \times 10^{-2}, \mathrm{y}_{p}=0.3 \mathrm{H}, \mathrm{b}=0.25 \mathrm{H}\right)$.

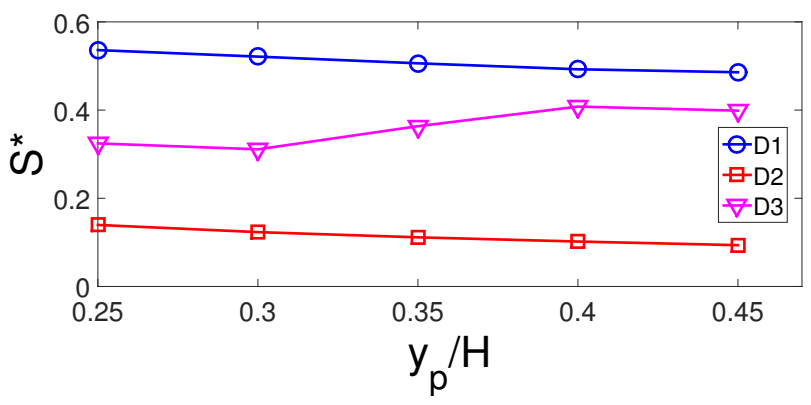

(a)

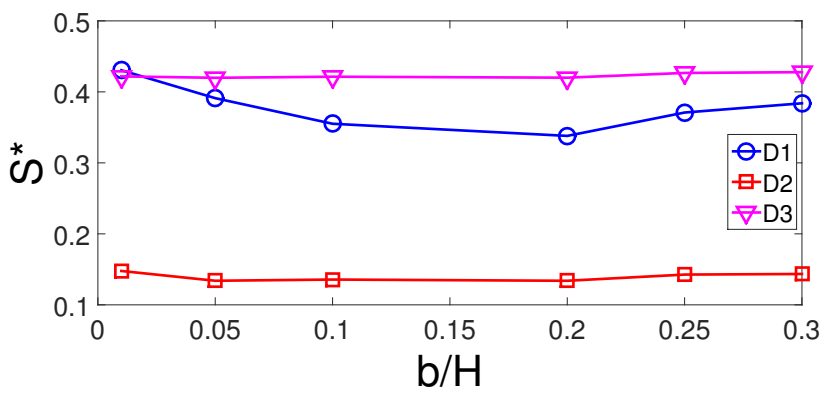

(c)

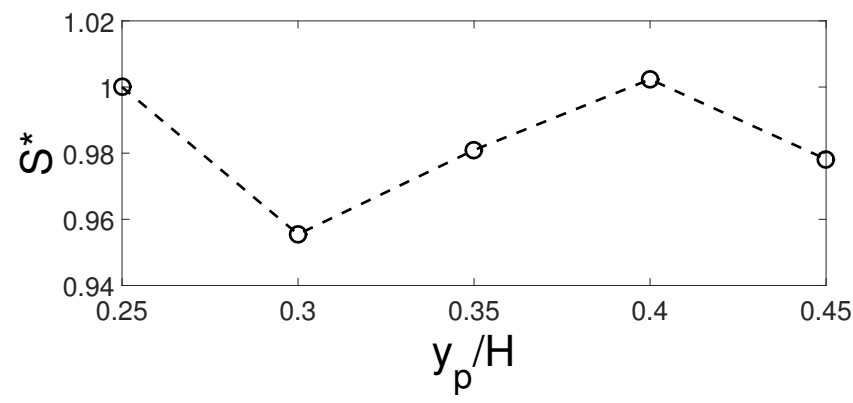

(b)

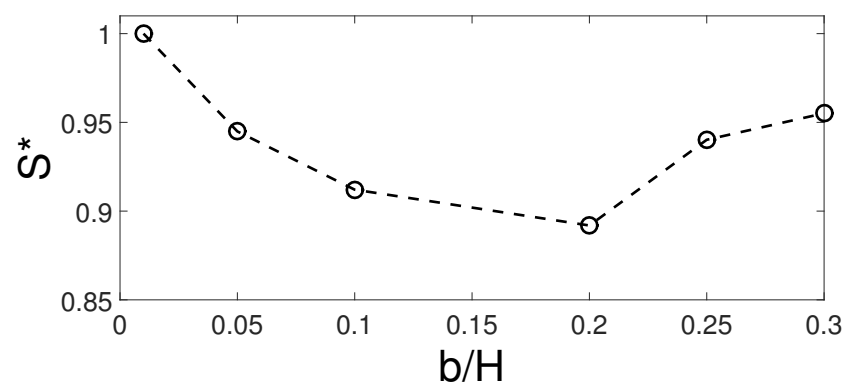

(d)

Figure 11. Normalized entropy generation $\left(S^{*}\right)$ variation of individual domains and all domains with respect to changes in porous layer location $(\mathbf{a}, \mathbf{b})$ and curvature size $(\mathbf{c}, \mathbf{d})\left(\operatorname{Re}=500, \mathrm{Ha}=15, \gamma=45^{\circ}, \mathrm{Da}=5 \times 10^{-2}, \mathrm{t}_{p}=0.3 \mathrm{H}\right)$. 


\section{Conclusions}

Impacts of a curved porous layer and MF on the forced CHT and entropy generation in a vented cavity are numerically explored. As the nanofluid velocity rises, the recirculation zone size below the inlet and vortex near the upper corner increases. The impact of Re number on the average $\mathrm{Nu}$ increment is significant for hot vertical walls. MF suppresses the vortices within the VC. The MF strength rises the average Nu of hot walls W1, W2, and W4 for Hartmann number above 20, while increment amounts are $47 \%, 38 \%$, and $38 \%$. However, EG also rises with highest MF strength and $22 \%$ increment is obtained when cases with and without MF effects are compared. The presence of the curved porous layer affects the CHT and EG of the vented cavity. As the permeability of the porous layer decreases, more fluid flows toward the walls below the inlet and bottom wall, resulting in $\mathrm{CHT}$ increment while the impact seems reverse for right and top hot walls. The increment of average $\mathrm{Nu}$ for wall below the inlet is $12.5 \%$ with lowest and highest permeability while variation is $21 \%$ for right vertical wall. The highest impact of varying height of the porous layer is obtained for wall below inlet port while highest variation in the average $\mathrm{Nu}$ is $9 \%$. There is 5\% reduction in the total EG when lowest and highest height of the porous layer cases are compared. The porous layer vertical position resulted in change of average $\mathrm{Nu}$ of $12.5 \%$ for left hot wall and $32.5 \%$ for right vertical wall. The lowest EG when varying location of porous layer is observed at $y_{p}=0.3 \mathrm{H}$ for all domains which is attributed to the heat transfer irreversibility. The highest impact of the curvature of the porous layer on the average $\mathrm{Nu}$ is attained for top wall which is $24 \%$. However, the total EG reduces with higher radius of the elliptic curvature and lowest value of the total EG is obtained at $b=0.2 \mathrm{H}$.

Author Contributions: F.S. performed the numerical simulations and wrote some sections of the manuscript. H.F.Ö. prepared some other sections of the paper and analyzed the results. All of the authors contributed equally for reviewing and revising the manuscript. All authors have read and agreed to the published version of the manuscript.

Funding: This research received no external funding.

Institutional Review Board Statement: Not applicable.

Informed Consent Statement: Not applicable.

Conflicts of Interest: The authors declare no conflict of interest.

\section{Abbreviations/Nomenclature}

$a, b \quad$ elliptic curvature radii

D domain

Da Darcy number

Ha Hartmann number

$h$ local heat transfer coefficient

$k$ thermal conductivity

$n$ unit normal vector

$\mathrm{Nu}_{s} \quad$ local Nusselt number

$\mathrm{Nu}_{m}$ average Nusselt number

$p$ pressure

Pr Prandtl number

$R \quad$ normalized residual

$r \quad$ neck curvature

Re Reynolds number 


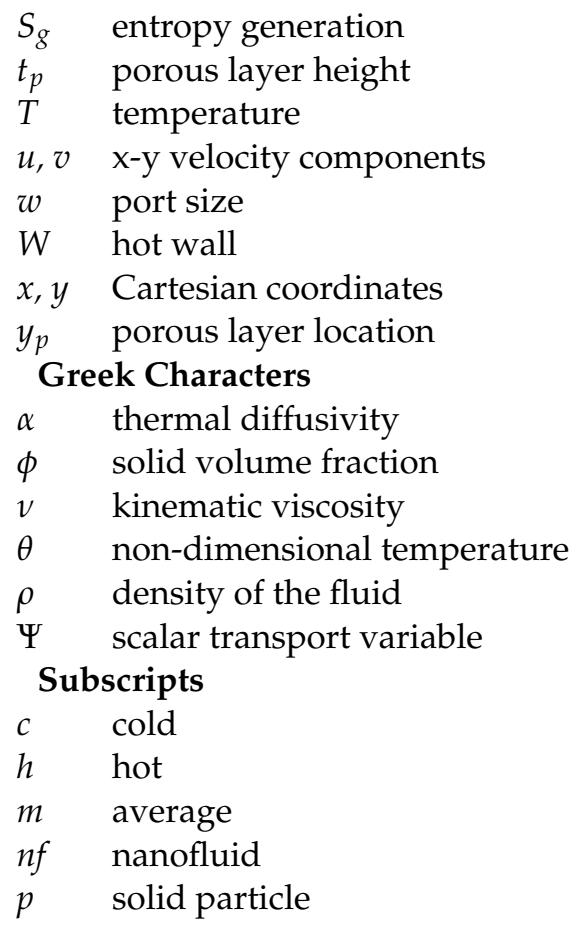

\section{References}

1. Saeidi, S.; Khodadadi, J. Forced convection in a square cavity with inlet and outlet ports. Int. J. Heat Mass Transf. 2006, 49, 1896-1906. [CrossRef]

2. Gibanov, N.S.; Sheremet, M.A.; Ismael, M.A.; Chamkha, A.J. Mixed convection in a ventilated cavity filled with a triangular porous layer. Transp. Porous Media 2017, 120,1-21. [CrossRef]

3. Chamkha, A.J.; Selimefendigil, F.; Oztop, H.F. Pulsating Flow of CNT-Water Nanofluid Mixed Convection in a Vented Trapezoidal Cavity with an Inner Conductive T-Shaped Object and Magnetic Field Effects. Energies 2020, 13, 848. [CrossRef]

4. Saeidi, S.; Khodadadi, J. Transient flow and heat transfer leading to periodic state in a cavity with inlet and outlet ports due to incoming flow oscillation. Int. J. Heat Mass Transf. 2007, 50, 530-538. [CrossRef]

5. Chikh, S.; Boumedien, A.; Bouhadef, K.; Lauriat, G. Analytical solution of non-Darcian forced convection in an annular duct partially filled with a porous medium. Int. J. Heat Mass Transf. 1995, 38, 1543-1551. [CrossRef]

6. Siavashi, M.; Bahrami, H.R.T.; Aminian, E. Optimization of heat transfer enhancement and pumping power of a heat exchanger tube using nanofluid with gradient and multi-layered porous foams. Appl. Therm. Eng. 2018, 138, 465-474. [CrossRef]

7. Guerroudj, N.; Kahalerras, H. Mixed convection in a channel provided with heated porous blocks of various shapes. Energy Convers. Manag. 2010, 51, 505-517. [CrossRef]

8. Miroshnichenko, I.V.; Sheremet, M.A.; Oztop, H.F.; Abu-Hamdeh, N. Natural convection of alumina-water nanofluid in an open cavity having multiple porous layers. Int. J. Heat Mass Transf. 2018, 125, 648-657. [CrossRef]

9. Astanina, M.S.; Sheremet, M.A.; Oztop, H.F.; Abu-Hamdeh, N. Mixed convection of Al2O3-water nanofluid in a lid-driven cavity having two porous layers. Int. J. Heat Mass Transf. 2018, 118, 527-537. [CrossRef]

10. Abd Elmaboud, Y.; Abdelsalam, S.I. DC/AC magnetohydrodynamic-micropump of a generalized Burger's fluid in an annulus. Phys. Scr. 2019, 94, 115209. [CrossRef]

11. Abdelsalam, S.I.; Mekheimer, K.S.; Zaher, A. Alterations in blood stream by electroosmotic forces of hybrid nanofluid through diseased artery: Aneurysmal/stenosed segment. Chin. J. Phys. 2020, 67, 314-329. [CrossRef]

12. Yazid, M.N.A.W.M.; Sidik, N.A.C.; Yahya, W.J. Heat and mass transfer characteristics of carbon nanotube nanofluids: A review. Renew. Sustain. Energy Rev. 2017, 80, 914-941. [CrossRef]

13. Ahammed, N.; Asirvatham, L.G.; Wongwises, S. Entropy generation analysis of graphene alumina hybrid nanofluid in multiport minichannel heat exchanger coupled with thermoelectric cooler. Int. J. Heat Mass Transf. 2016, 103, 1084-1097. [CrossRef]

14. Sadaf, H.; Abdelsalam, S.I. Adverse effects of a hybrid nanofluid in a wavy non-uniform annulus with convective boundary conditions. RSC Adv. 2020, 10, 15035-15043. [CrossRef]

15. Selimefendigil, F.; Öztop, H.F. The potential benefits of surface corrugation and hybrid nanofluids in channel flow on the performance enhancement of a thermo-electric module in energy systems. Energy 2020, 213, 118520. [CrossRef]

16. Mansour, M.A.; Siddiqa, S.; Gorla, R.S.R.; Rashad, A.M. Effects of heat source and sink on entropy generation and MHD natural convection of Al2O3-Cu/water hybrid nanofluid filled with square porous cavity. Therm. Sci. Eng. Prog. 2018, 6, 57-71. [CrossRef] 
17. Sajjadi, H.; Delouei, A.A.; Izadi, M.; Mohebbi, R. Investigation of MHD natural convection in a porous media by double MRT lattice Boltzmann method utilizing MWCNT Fe3O4/water hybrid nanofluid. Int. J. Heat Mass Transf. 2019, 132, 1087-1104. [CrossRef]

18. Abdelsalam, S.; Bhatti, M. Anomalous reactivity of thermo-bioconvective nanofluid towards oxytactic microorganisms. Appl. Math. Mech. 2020, 41, 711-724. [CrossRef]

19. Bejan, A. Second-law analysis in heat transfer and thermal design. In Advances in Heat Transfer; Elsevier: Amsterdam, The Netherlands, 1982; Volume 15, pp. 1-58.

20. Sheikholeslami, M.; Jafaryar, M.; Shafee, A.; Li, Z.; Haq, R.u. Heat transfer of nanoparticles employing innovative turbulator considering entropy generation. Int. J. Heat Mass Transf. 2019, 136, 1233-1240. [CrossRef]

21. Hussain, S.; Ahmed, S.E.; Akbar, T. Entropy generation analysis in MHD mixed convection of hybrid nanofluid in an open cavity with a horizontal channel containing an adiabatic obstacle. Int. J. Heat Mass Transf. 2017, 114, 1054-1066. [CrossRef]

22. Mehrez, Z.; Cafsi, A.E.; Belghith, A.; Quere, P.L. MHD effects on heat transfer and entropy generation of nanofluid flow in an open cavity. J. Magn. Magn. Mater. 2015, 374, 214-224. [CrossRef]

23. Astanina, M.S.; Sheremet, M.A.; Oztop, H.F.; Abu-Hamdeh, N. MHD natural convection and entropy generation of ferrofluid in an open trapezoidal cavity partially filled with a porous medium. Int. J. Mech. Sci. 2018, 136, 493-502. [CrossRef]

24. Ma, Y.; Mohebbi, R.; Rashidi, M.M.; Yang, Z. MHD convective heat transfer of Ag-MgO/water hybrid nanofluid in a channel with active heaters and coolers. Int. J. Heat Mass Transf. 2019, 137, 714-726. [CrossRef]

25. Esfe, M.H.; Arani, A.A.A.; Rezaie, M.; Yan, W.M.; Karimipour, A. Experimental determination of thermal conductivity and dynamic viscosity of Ag-MgO/water hybrid nanofluid. Int. Commun. Heat Mass Transf. 2015, 66, 189-195. [CrossRef]

26. Maxwell, J.C. A Treatise on Electricity and Magnetism; Clarendon Press: Oxford, UK, 1873; Volume 1.

27. Tayebi, T.; Chamkha, A.J. Entropy generation analysis due to MHD natural convection flow in a cavity occupied with hybrid nanofluid and equipped with a conducting hollow cylinder. J. Therm. Anal. Calorim. 2020, 139, 2165-2179. [CrossRef]

28. Selimefendigil, F.; Öztop, H.F. Modeling and optimization of MHD mixed convection in a lid-driven trapezoidal cavity filled with alumina-water nanofluid: effects of electrical conductivity models. Int. J. Mech. Sci. 2018, 136, 264-278. [CrossRef]

29. Minea, A.A.; Luciu, R.S. Investigations on electrical conductivity of stabilized water based $\mathrm{Al}_{2} \mathrm{O}_{3}$ nanofluids. Microfluid. Nanofluid. 2012, 13, 977-985. [CrossRef]

30. Chereches, E.I.; Minea, A.A. Electrical conductivity of new nanoparticle enhanced fluids: An experimental study. Nanomaterials 2019, 9, 1228. [CrossRef]

31. Fluent, A. Ansys Fluent 12.0 Theory Guide; ANSYS Inc.: Canonsburg, PA, USA, 2009.

32. Versteeg, H.; Malalasekera, W. An Introduction to Computational Fluid Dynamics. The Finite Volume Method, 2nd ed.; Pearson Prentice Hall: Upper Saddle River, NJ, USA, 2007.

33. Leonard, B.P. A stable and accurate convective modelling procedure based on quadratic upstream interpolation. Comput. Methods Appl. Mech. Eng. 1979, 19, 59-98. [CrossRef]

34. Patankar, S. Numerical Heat Transfer and Fluid Flow; Hemisphere / McGraw-Hill: New York, NY, USA, 1980.

35. Sourtiji, E.; Gorji-Bandpy, M.; Ganji, D.; Hosseinizadeh, S. Numerical analysis of mixed convection heat transfer of Al2O3-water nanofluid in a ventilated cavity considering different positions of the outlet port. Powder Technol. 2014, 262, 71-81. [CrossRef]

36. Ghasemi, B.; Aminossadati, S.; Raisi, A. Magnetic field effect on natural convection in a nanofluid-filled square enclosure. Int. J. Therm. Sci. 2011, 50, 1748-1756. [CrossRef]

37. Baytaş, A. Entropy generation for natural convection in an inclined porous cavity. Int. J. Heat Mass Transf. 2000, 43, 2089-2099. [CrossRef]

38. Saeid, N.H.; Pop, I. Transient free convection in a square cavity filled with a porous medium. Int. J. Heat Mass Transf. 2004, 47, 1917-1924. [CrossRef]

39. Sheremet, M.A.; Oztop, H.; Pop, I.; Al-Salem, K. MHD free convection in a wavy open porous tall cavity filled with nanofluids under an effect of corner heater. Int. J. Heat Mass Transf. 2016, 103, 955-964. [CrossRef] 